(2) institute of development studies

\title{
Decentralised Cooperation and Local Government: Addressing Contemporary Global Challenges
}

Jaideep Gupte and Saba Aslam

February 2022 


\section{Prelims}

\section{Suggested citation}

Gupte, J. and Aslam, S. (2022) Decentralised Cooperation and Local Government: Addressing Contemporary Global Challenges, Brighton: Institute of Development Studies, DOI: 10.19088/IDS.2022.002

\section{Authors}

Jaideep Gupte and Saba Aslam

Published February 2022

\section{Funding and competing interests}

This publication has been produced through generous funding from the Generalitat de Catalunya, and with other contributions from the city of Barcelona, the Federation of Canadian Municipalities, the international cooperation agency of the Association of Netherlands Municipalities (VNG International) and the European Union and the government of Sweden, through their grant to United Cities and Local Governments. The views expressed herein do not necessarily reflect the views of the supporting organisations.

No potential conflict of interest was reported by authors.

\section{Licensing}

\section{(cc) BY-NC}

This is an Open Access article distributed under the terms of the Creative Commons Attribution Non-Commercial 4.0 International licence (CC BY-NC), which permits use, distribution and reproduction in any medium, provided the original authors and source are credited, any modifications or adaptations are indicated, and the work is not used for commercial purposes.

\section{Copyright}

(c) 2022 The Authors.

Available from:

Institute of Development Studies, Library Road

Brighton, BN1 9RE, United Kingdom

+44 (0)1273915637

ids.ac.uk

IDS is a charitable company limited by guarantee and registered in England.

Charity Registration Number 306371

Charitable Company Number 877338 


\section{Contents}

Acknowledgements $\quad$ v

Acronyms $\quad v$

Executive Summary vii

Defining decentralised cooperation and the context in which it must operate vii

Key findings viii

Future directions for decentralised cooperation $\quad$ xi

Policy recommendations for associations and networks of local and regional governments and authorities xii

Section One: Introduction 1

$\begin{array}{ll}\text { Background } & 1\end{array}$

Methodology and process 2

Achievements of decentralised cooperation to date 4

Summary of the 2013 Policy Paper on Decentralised Cooperation 5

Recommendations of the 2013 study 6

Section Two: Why decentralised development cooperation matters in light of contemporary risks, challenges and opportunities 8

Understanding contemporary risks, challenges, and opportunities $\quad 8$

Ecological transformation and cascading risks 8

Covid-19 and (Post)pandemic recovery 9

Accessing Green Finance 10

Current state of decentralised cooperation 11

$\begin{array}{ll}\text { Scholastic advancements } & 11\end{array}$

Growing consensus on defining decentralised cooperation 15 
Local service provision and decentralised cooperation

Evolution of networks for decentralised cooperation and their contribution to global agendas

The Town Hall

Section Three: Responding to global challenges through decentralised cooperation

How do UCLG network members contextualise development cooperation in relation to contemporary global challenges?

Ecological transformations and climate risks

Covid-19 and post-pandemic recovery

How has the work of LRGs and LRGAs been affected by the Covid-19 crisis?

Perspectives on the role of local and regional governments during the Covid-19 crisis and its aftermath

What is the role of LRGs and LRGAs in the aftermath of the Covid-19 crisis?

What specific role could UCLG, its members and its network play?

Gendered inequalities, and unequal access to basic services

Accessing Green Finance

Workshop on Local Government and Development Cooperation

Operations and engagement with cooperation institutions and infrastructures (analogue and digital)

Partnerships and engagement

Financing

Section Four: Future directions for decentralised cooperation: what, where, with whom and how

Bibliography

Annexe 1.1: Questionnaire 


\section{Table of Figures}

Figure 1: UCLG Priority Themes in the current global context 3

Figure 2: Methodology and study approach 3

Figure 3: Number of publications and citations on 'decentralised cooperation and local government' increased significantly after 2004, and again after 2007

Figure 4: Tree-maps illustrating 479 studies identified by academic disciplines, or research and by funding agency.

Figure 5: Locations of survey responses 28

Figure 6: Location of responding organisation $\quad 29$

Figure 7: Level of Cooperation Partnerships 29

Figure 8: Type of Cooperation Partnerships 30

Figure 9: Types of evidence used in setting organisational priorities 30

Figure 10: Primary means of identifying at-risk or vulnerable groups 31

\section{Table of Tables}

Table 1: Lead academic disciplines or research areas and prominent funding agencies, where identifiable, for published studies on decentralised cooperation 


\section{Acknowledgements}

Key stakeholders consulted: Emilia Saiz (UCLG Secretary General), Jean-Baptiste Buffet (UCLG Policy), Mathilde Penard (UCLG Local Finance), Edgardo Bilsky (UCLG Research), Ashley Palmer (Global Partnership for Effective Development Cooperation), Rebakah Chew (United Nations Development Programme), Sarah Bentz (CEMR-PLATFORMA), Amandine Sabourin (CEMR-PLATFORMA), Sogen Moodley (Durban University of Technology), Vesco Ghélew Nathalie (Swiss Agency for Development and Cooperation), Bernadia Tjandradewi (UCLG ASPAC), Susan Parnell (University of Bristol), John Gaventa (Institute of Development Studies), Aromar Revi (Indian Institute for Human Settlements), Diana Mitlin (University of Manchester), Pascal Lavoie (Federation of Canadian Municipalities), Elena Pierce (Federation of Canadian Municipalities), Javier Sánchez Cano (Region of Catalonia, ORUFOGAR), Jessie Post (VNG International, CIB working group), Sara Hoeflich (UCLG Learning), Peter Knip (VNG International), Alice Balbo (German Association of Cities), Monica Graciela Solorzano Soto (FLACMA), Lucy Slack (CLGF), UCLG Regional Sections, UCLG Learning Team, CIB working group Reference Group

Authors wish to acknowledge invaluable support from Jorge Ortiz-Moreno and Rosa Lewis-Anthony, and Blossom Carrasco for layout and illustrations of the case studies.

\section{Acronyms}

$\begin{array}{ll}\text { ACI } & \text { Agencia de Cooperación e Inversión de Medellín } \\ \text { AFD } & \text { Agence Française de Développemen } \\ \text { BRICS } & \text { Brazil, Russia, India, China, and South Africa } \\ \text { CEMR } & \text { Council of European Municipalities and Regions } \\ \text { CGIAR } & \text { Consultative Group on International Agricultural Research } \\ \text { CIB } & \text { Capacity and Institution Building Working Group } \\ \text { CLGF } & \text { Commonwealth Local Government Forum } \\ \text { Covid-19 } & \text { SARS-CoV-2 } \\ \text { DAC } & \text { Development Assistance Committee } \\ \text { DDR } & \text { Disaster Risk Reduction } \\ \text { DFG } & \text { German Research Foundation } \\ \text { DFID } & \text { Department for International Development } \\ \text { EU } & \text { European Union } \\ \text { FCDO } & \text { Foreign Commonwealth and Development Office } \\ \text { FLACMA } & \text { Federación Latinoamericana de Ciudades, Municipios y } \\ & \text { Asociaciones de Gobiernos Locales } \\ \text { GCoM } & \text { Global Covenant of Mayors } \\ \text { GIZ } & \text { Deutsche Gesellschaft für Internationale Zusammenarbeit } \\ \text { GOLD } & \text { Global Observatory on Local Democracy and Decentralization } \\ \text { GPEDC } & \text { Global Partnership for Effective Development Co-operation }\end{array}$




\begin{tabular}{ll} 
GTF & Global Task Force \\
HLF-4 & High-Level Forum on Aid Effectiveness \\
ICLEI & Local Governments for Sustainability \\
ICREA & Catalan Institution for Research and Advanced Studies \\
INGO & International Non-Governmental Organisation \\
IT & Information Technology \\
LED & Local Economic Development \\
LG & Local Governments \\
LGBTQ+ & Lesbian, Gay, Bisexual, Transgender, Queer, Plus \\
MDGs & Millennium Development Goals \\
MEL & Monitoring, Evaluation and Learning \\
NALAS & Network of Associations of Local Authorities of South-East \\
& Europe \\
NGO & Non-Governmental Organisations \\
NSF & National Science Foundation \\
NWO & Netherlands Organization for Scientific Research \\
OEDC & Organisation for Economic Co-operation and Development \\
PPE & Personal Protective Equipment \\
SALGA & South African Local Government Association \\
SDC & Swiss Agency for Development and Cooperation \\
SDGs & Sustainable Development Goals \\
SIDA & Swedish International Development Cooperation Agency \\
SNSF & Swiss National Science Foundation \\
SP & Social Protection \\
SSC & South-South Cooperation \\
UCLG & United Cities and Local Governments \\
UKRI & UK Research and Innovation \\
UN ECOSOC & United Nations Economic and Social Council \\
UNGA & United Nations General Assembly \\
UN & United Nations \\
US & United States \\
USAID & United States Agency for International Development \\
VNG & Association of Netherlands Municipalities \\
\hline
\end{tabular}




\section{Executive Summary}

At the start of the last decade, United Cities and Local Governments' (UCLG) policy paper on Decentralised Cooperation and Local Government ${ }^{1}$ laid out a clear rationale for decentralised cooperation and set out recommendations to the prevalent tackle weaknesses of international development cooperation and to strengthen development effectiveness. In many ways, the paper was a forerunner in calling for stronger sustained support for South-South development cooperation particularly among countries that have undergone similar socio-economic challenges so that learnings can be shared across partners. It laid emphasis on professional structures and programme-based approaches, with clear monitoring and evaluation tools and indicators on impact and called for a sharing of objectives across local and regional governments, and their associations, committed to continuing improvement, learning and exchange. These recommendations have helped strengthen international decentralised cooperation over the past decade, and their core principles continue to be highly relevant today.

In 2021, the Institute of Development Studies, UK, with support of the UCLG Capacity and Institution Building Working Group (CIB), has engaged a wide range of member governments, associations, and networks, alongside a range of external commentators and experts, to assess UCLG principles, priorities, and actions in the context of contemporary global challenges and the resulting landscape of decentralised development cooperation. Following a series of survey-based, individual, case study, and workshop interactions, the study presents the following key points and recommendations:

\section{Defining decentralised cooperation and the context in which it must operate}

'Decentralised cooperation' is understood as development cooperation between local and regional authorities and their networks and associations. It is understood as being:

(a) Multi-layered, involving actors, actions, and objectives at the local, regional, national, and international levels.

(b) Multi-dimensional, involving multiple actors (elected, appointed, and customary) across multiple sectors (public, private, and third sector)

(c) Responsive to 21st century developmental challenges, risks, and opportunities.

In this paper, we describe the contemporary context in which decentralised cooperation must operate as shaped by four key challenges. These include (i) rapid

\footnotetext{
${ }^{1}$ See https://www.local2030.org/library/42/Development-Cooperation-and-Local-Government.pdf
} 
climate and ecological transformation, and the multiple and cascading risks faced by least-resourced and most-marginalised urban and rural residents particularly in, but not limited to, low- and middle-income countries. Particularly relevant to Local and Regional Governments and Authorities (LRGs) and Local and Regional Government Associations and Networks (LRGAs) is that rapid climate change has hastened the transition from crisis management to multi-hazard risk-informed urban planning and decision-making. (ii) Direct health and health systems impacts of Covid-19, as well as the long-term implications for recovery, and the responsibilities of local governments in awareness raising, provision of key infrastructure and services, as well as collaboration. (iii) Addressing gendered and socio-economic inequalities in accessing basic services and infrastructures. And (iv) achieving sustainable development through financing or refinancing new and existing public and private investments that explicitly have environmental objectives.

\section{Key findings}

We chart the evolution of decentralised cooperation over the past three decades, and note the significant materialisation of a distinct identity, notably amongst several local and regional networks, and through the leadership of the Global Task Force. Subnational membership of local/regional authorities and an increasingly decentralised structure is recognised as a particular strength to carry out a cross-sectoral mandate. In relation to transnational and global compacts, LRGAs such as UCLG have shown notable leadership in the New Urban Agenda (with a focus on cities, and localisation), the Paris Agreement (positioning the role of decentralisation in climate change and Net Zero), the Sendai framework (with a focus on risk reduction and resilience), the Addis agenda (with a focus on local finance) and the Beijing declaration (with a focus on gender). In addition to these important roles in transnational and global compacts, decentralised cooperation is carried out through key international institutions, networks, and associations of local and regional actors, including for example the Parliament of Mayors (supported by the European Union (EU)), a strategically important platform.

The study found that the new ways of working centred around learning, advocacy and research are relevant and appropriate. Stakeholders described these ways of working as moving away from abstract ideas of 'co-learning' and building a realistic learning agenda to bring people together to discuss common problems and arrive at solutions. In this regard, Covid-19 has spurred a 'digital turn', with much increased participation online. There is now a need to sustain this through peer-to-peer learning, advocacy, and research, as well as allow the changes to be reflected in UCLG's organisational structure - from the executive board and policy councils to regional sections, working groups and committees, as well as key UCLG reports (for example, Global Observatory on Local Democracy and Decentralization (GOLD) Reports) and member reporting practices (for example, voluntary reporting on Sustainable Development Goals (SDGs)). Members found that digital spaces can enable participation, learning, 
and consensus building, but have also become spaces for surveillance, curtailing of citizenship rights, unsavoury kind of trends in the community. Therefore, digital engagement is desired, but requires carefully thought-out strategy that shows a transparent purpose, and efficient implementation.

Members recognised the conscious effort on the part of LRGAs to include local and regional authorities within different transnational statements and positions. Moving forward this can be more cohesive in bringing together various agendas and initiatives under the broad umbrella of tackling global challenges. Town hall meetings, a format championed by UCLG, are an important consensus building platform, and regional sections are an appropriate scale at which such consensus building can coalesce. LRGAs can consider the extent to which it wants to actively encourage its membership to participate in and implement a development cooperation agenda built around core cooperation principles and priorities. In other words, what 'value' will the LRGAs place on being a member over the coming decade? What should national governments, donors, civil society, local and regional governments be held accountable for them to fulfil their responsibilities as 'development actors'?

Stakeholders identified that training a cadre of local and regional authorities in core values of peer-to-peer/reflexive learning and decentralised cooperation, involves placing reflexivity and cooperation as desired objectives, as well as the means to achieving those objectives. Development cooperation stakeholders share a responsibility to encourage a healthy 'bureaucratic mobility', involving opportunities for national stakeholders at the local/regional level and vice versa. Where such mobility already exists, stakeholders must celebrate the success and share the lessons learned. Where it does not occur to the desired extent, LRGAs must advocate for it as a new modality in decentralised cooperation. This extends to local and regional politicians, across political spectrums, who should themselves continue to be welcomed into international diplomacy forums.

LRGAs such as UCLG are uniquely placed to recognise the new and changing differences and competition between cities, regions and countries while still promoting development cooperation. This notwithstanding, members expressed a tangible concern over diminished financial resources, made more acute due to the impacts of Covid-19. There is a desire to shift from 'crises driven' fund raising, and towards a longer-term strategy focused on resilience. Driving this concern is the changing landscape of international development funding in the global north (where such funds are increasingly scarce and subject to ever greater levels of scrutiny), as well as across emerging and southern country contexts (where 'Rising Powers' are displaying their desire to influence international development trajectories in new ways). Members and commentators recognise that decentralised cooperation consists of complex relational geographies, that simultaneously extend from City-to-City, region-to-region as well as across various national, bilateral, and multilateral stakeholders, who are themselves networked in a variety of ways. Members and commentators held differing 
views on what the purpose of decentralised cooperation is but agreed that the SDGs cannot be achieved without it and were generally positive on the role UCLG can play in finding common ground between subnational actors to further cooperation. As a powerful collective with many members, LRGAs should focus on revenue models that are not just dependent on particular geographies and donors, but instead develop entrepreneurial connection across cities and regions, with a much stronger engagement between South-South geographies. Improving access to information across members and reducing language barriers are important modes of bridging gaps and bringing missing stories from a range of geographies.

The study identified a broad and healthy consensus that decentralised cooperation is not simply about adding or devolving responsibilities to the local level. It must be recognised as producing an effective governmental system that provides the right path for international cooperation to exist between the appropriate levels of government. There are hundreds of active networks that involve subnational actors, many of them are focused on specific issues (for example, inequality or affordable housing) or challenges (for example, responding to climate change). Not all are able to address decentralised cooperation. Commentators recognised that LRGAs can contribute to the theoretical as well as practical advancement of decentralised cooperation, and that development challenges cannot be met without effective local governance. This moves the objectives of decentralised cooperation such that LRGs and LRGAs are afforded the right spaces that allow healthy, transparent dialogue with development actors to happen. A global network like UCLG is uniquely positioned to foster this relationship and those kinds of learnings between various actors in governance. Related to this, stakeholders identified that the global monitoring exercise needs to move beyond a donor-recipient relationship, and not remain focused on the aideffectiveness architecture alone. Key questions remain on what frameworks could enable greater participation of sub-national actors in development cooperation, and how LRGAs fit within the accountability landscape of global monitoring.

Finally, carrying out development cooperation in fragile and conflict-affected contexts was identified as a key concern with regards to dealing with a range of actors, developing trust, and gaining legitimacy. Equally, LRGAs are well positioned to foster discussions on deepening democratic governance in a context of rising authoritarianism and shrinking civic spaces (Freedom House report underscores curtailing of freedoms). Stakeholders caution the rise of 're-centralisation of powers' with central governments taking back their control of civil society actors, as well as local governance actors. LRGAs could take further steps to strengthen relationships between citizens and governments to protect democratic spaces that strengthen relationships between citizens and different tiers of governments. 


\section{Future directions for decentralised cooperation}

The study concludes by offering a set of generalisable principles that can be used to determine the future directions for decentralised cooperation. The field of decentralised cooperation is now well established in the scholarly literature. This mirrors the dynamism evident in the guiding principles and strategic visions being set by local and regional authorities and their associations. These are in keeping with the recognition of decentralised cooperation as one of the mainstays of any serious pursuit of sustainable development. The urgent and intensifying nature of global challenges, as well as opportunities and innovation inherent at the local and regional level imply an ever-increasing responsibility for local and regional actors.

As such, networks and associations must be driven by a central objective to empower and enable local and regional actors, and at the same time, they must continue to be open and inviting to actors operating at non-local scales. Collaborative capacity strengthening (co-learning) presents a key pathway to meet current and future organisational challenges. This specifically includes bridging the gender gap and including more women's voices particularly where the number of elected women remains low. Strategic actions to align learning and advocacy efforts will help identify locally relevant themes, reflexively determine how curricula should be defined, and strategically build relationships with United Nations (UN) bodies, as well as with national forums.

Finally, it is pertinent for networks of cities, as well as those of or for local governments to focus their efforts on cities, city-regions, and sub-national regions where urban change is greatest, and therefore significantly impacting local development. This necessarily places the fast-urbanising regions in Asia (China, India) and in Africa (for example, a selection of countries with the highest urban growth rates include Burundi, Burkina, Ethiopia, Madagascar, Angola, and Nigeria) as a priority. Local and regional governments and authorities already have an impressive range of collaborative and multi-scalar partnerships through their networks and associations, and these are built on mutual trust and respect for individual mandates. As LRGAs responds to the changing nature of contemporary challenges, they must consider how new strategic partnerships, for example with university and research stakeholders, can help strengthen evidence-based action, and help position LRGAs in relation to key debates (for example on climate, security, inequality etc.). The evidence base is also critical in understanding and aligning with changing donor priorities. 


\title{
Policy recommendations for associations and networks of local and regional governments and authorities
}

\author{
Introduction
}

1. The past decade has been characterised by various global grand challenges. While tremendous progress has been made towards meeting these problems, the following contemporary issues continue to define the most significant obstacles to, and opportunities arising out of, development:

a) Ecological transformation and the multiple and cascading risks faced by least-resourced and most-marginalised urban and rural residents (particularly in, but not limited to, low- and middle-income countries).

b) (Post-) Covid-19 recovery: Covid-19, its impacts, and the consequences of policy responses, particularly as experienced by the most marginalised and least resourced women, men, and children in the global South and North, require reflection of course. But the key for the localisation/decentralisation cooperation agenda is to ascertain how the heightened risks and vulnerabilities create longer term and broader systems implications.

c) Addressing gendered and socio-economic inequalities in accessing basic services and infrastructures: the world is facing a $\$ 15$ trillion infrastructure gap by 2040 . One in three people globally do have access to safe drinking water and sanitation, while over half of the world's population do not have access to adequate and affordable health services. In cities and towns, close to one billion people live in under-serviced informal settlements. Women, men, girls, and boys experience these inequalities and related challenges differently.

d) Access to finance: the current situation of local government finance can be characterised as weak financial autonomy, paucity of their own income, uneven and volatile intergovernmental fiscal transfers and extremely limited (if not purely impossible) access to credit and capital markets. Furthermore, local economies are heavily relying on small and micro businesses ( $~ 80$ per cent), the majority of which are informal. There is an urgent need for national governments/states to 
increase local government capacity to modify tax structures, so they are in line with their underlying economic bases. This could be realised by widening the local government tax base, leading to increased flexibility to collect a better mix of taxes. Furthermore, it is time to help local governments to access capital markets.

2. These contemporary issues are themselves shaped by a range of enabling and limiting drivers:

a) Cultural diversity. The world requires respect for cultural diversity, as a source of knowledge, as a vital element of citizenship and as a component for peaceful resolution of conflicts. Cultural cooperation is also the vehicle to heal the consequences of colonialism and to decrease of the high levels of inequality. Cities and local regions are not only important platforms on which cultural diversity and heritage is celebrated, they also present opportunities for intercultural responses to development challenges.

b) Opportunities and challenges associated with informal work, housing, and basic services.

3. Development cooperation takes place within this continuously changing context. As a result, international agendas and compacts evolve, donor-recipient relations change, modalities are adapted, donors shift their priorities.

4. Local governments and their associations operate within this dynamic context, as ideators, implementers, sparring partners and experts from the field.

5. In the past decade, the international policy context and national and international actors of development have formally recognised the role of local governments as leading actors and agents of development. UCLG, along with other key international networks, has championed the power of local governments to drive positive change.

6. This is reflected in the direct references to the work and responsibilities of local governments in the new international agendas (Agenda2030 for sustainable development, the New Urban Agenda, the Paris agreement), seats at important forums and consultations (i.e. Global Partnership for Effective Development Cooperation, Organisation for Economic Cooperation and Development (OECD), United Nations Economic and Social Council (UN ECOSOC)) and an increasingly open debate about a place for local governments in the international multilateral system, in the light of the celebration of 75 years of United Nations, in 2020. 
7. The Covid-19 pandemic further highlights the stronger need to acknowledge cooperation at all levels, including at local and regional level, in contrast to the competition which we sometimes see between national governments.

\section{Changes since 2013: The impact of global challenges and the new international agendas on development}

8. While there has been much effort and success in the global effort to tackle the major challenges to sustainable and inclusive development mentioned above, some of these global challenges have intensified over the past decade.

9. As a result, a suite of international compacts and agendas have established, strengthened, and renewed the global effort.

10. Local and regional governments have specific roles and responsibilities in this changed landscape. Local governments help to build a world of solidarity through i) guaranteeing public services, ii) boosting proximity models of global consumption and production, iii) tackling the effects of global warming and developing climate adaptation and mitigation strategies iv) facilitating new citizenship and freedoms for renewed democracy and v) strengthening gender and generational equality and fostering inclusive democracy and social cohesion, among many other tasks and responsibilities. Notwithstanding these devolved governance responsibilities, which allow greater local agency and policy autonomy, local governments and authorities face strained limited financial and personnel capacities.

11. The international agendas which have been adopted in recent years have also clearly impacted the development sector. The world has become more complex and interconnected; a development which called for new frameworks which introduced new narratives, values, rules, and goals.

12. The Agenda 2030 loudly calls for universality and for integrated solutions based on the lessons learned from the Millennium Agenda, which was focused on the North helping the South. The 2015 Paris climate agreement calls for worldwide commitment to slow down climate change and aims to strengthen the ability of countries to deal with the impacts of climate change. The New Urban Agenda represents a shared vision for a better and more sustainable future and creates another direct link, as accelerator of the SDGs between, local governments and the 2030 Agenda. If wellplanned and well-managed, urbanisation can be a powerful tool for sustainable development for both developing and developed countries. 
13. These international agendas and the objectives that they strive for have trickled down to everyday business of local governments, all around the world.

\section{Characteristics of local government development cooperation in 2021}

14. Local government development cooperation has never been an end in itself; it should be regarded as one of the key instruments to localise the international agendas and to tackle global challenges at local level, in view of reaching greater effectiveness.

15. Many donor organisations/funders of development cooperation are increasingly concerned with issues of climate change and economic growth and have integrated these global challenges and topics into their development cooperation policies, leading to relevant shifts in policies and budgets. Cities are seen as the front lines of climate change risk and response, while economic growth is seen as being driven by urban economies. Over the past decade, there has been a continuation of support for development assistance that more directly addresses urban poverty (e.g., World Bank), enabling urban economies for inclusive growth (e.g., Department for International Development (DFID)/Foreign Commonwealth and Development Office (FCDO)), technical assistance to local governments (e.g., Deutsche Gesellschaft für Internationale Zusammenarbeit (GIZ), Agence Française de Développement (AFD)). Various other donors have also focused on issues such as governance or basic education (e.g., Swiss Agency for Development and Cooperation (SDC)). Networks of cities such as UCLG have also provided a key step for the inclusion of smaller towns and secondary cities.

16. LRGA stakeholders, including UCLG members, express a tangible concern over diminished financial resources, made more acute due to the impacts of Covid-19. There is a desire to shift from 'crises driven' fund raising, and towards a longer-term strategy focused on resilience. Driving this concern is the changing landscape of international development funding in the Global North (where such funds are increasingly scarce and subject to ever greater levels of scrutiny), as well as across emerging and Southern country contexts (where 'Rising Powers' are displaying their desire to influence international development trajectories in new ways).

17. Within the local government development cooperation sector, a strong Global North-Global South orientation can still be witnessed, but SouthSouth cooperation and triangular cooperation (North-South-South) have become more prevalent and prominent. Donor organisations stimulate these forms of cooperation because they assume in-country and local ownership, which should help boost development effectiveness and is in line with the key principles behind the Sustainable Development Goals. The 
UCLG constituency favours a transition towards a more open and reciprocated form of development cooperation.

18. LRGA stakeholders, including UCLG members recognise the need to also train local and regional governments themselves, with regard to the core values of peer-to-peer/reflexive learning and (the added value of) development cooperation between local government, to make sure the constituency remains active in this field, also in times of diminishing (inter)national funding. Development cooperation stakeholders share a responsibility to encourage a healthy 'bureaucratic mobility', involving opportunities for national stakeholders at the local/regional level and vice versa. Where such mobility already exists, stakeholders must celebrate the success and share the lessons learned. Where it does not occur to the desired extent, advocate for it as a new modality in decentralised cooperation. This extends to local politicians, across political spectrums, who should themselves continue to be welcomed into international diplomacy forums.

19. For the moment, international partnerships and programmes between local governments remain inherently diverse and can focus on, among many other topics, (i) promoting peace and cultural dialogues, (ii) mutual learning, (iii) capacity building for local governments (and/or their associations), (iv) enhancing trade and investment, ( $v$ ) developing strategy and partnerships for local development and decentralised cooperation, (vi) tackling global issues like climate change.

20. Partnerships and programmes come in various forms, ranging from the more traditional 'city-to-city partnerships', to region-to-region cooperation, to international platforms and complex multi-stakeholder partnerships in which universities and private sector also play their part, besides local governments. All around the world, the nature of relationships, networks of solidarity and the spaces to political discourse are changing. In that context, there seems to be a larger understanding and appreciation of the coordinating role of local governments, in relation to NGOs, humanitarian organisations, private sector (formal and informal), and citizens, also in development.

21. Focus on Monitoring, Evaluation and Learning (MEL) within programmes of local government development cooperation has become increasingly important, in view of scrutiny demanded by taxpayers in donor countries, the local, regional, national political pressures this can generate, and (in some countries) the resulting budget cuts in development cooperation. The economic fallouts of Covid-19 and the public health measures put in place in response to the pandemic, have further increased the pressure on funding available for development cooperation. In times of domestic crisis, it may be less evident to spend budgets on international and development 
cooperation and therefore even more relevant to account for its results and added value. However, it is important to emphasise that being accountable to donor organisations is not the only reason for local government development cooperation actors to perform MEL activities; learning, innovation and transparency are important drivers too.

22. Many actors believe that the Covid-19 crisis (and subsequent economic and social crises) will have lasting impact on the ways of working of local government actors and development cooperation donors in the sector. The new realities and paradigms forced CIB members to review ongoing programmes, to invest in digital working environments, at home and abroad, and in distant learning and delivery methods, tools, and techniques.

23. Furthermore, beneficiaries of international municipal cooperation programmes will have to review their local (or regional) development plans, as the current planning and policies will have become outdated in the current crisis, at least to some extent. Structural decentralisation of tasks to partners in the Global South, as well as increased local ownership and enhanced South-South cooperation are essential ingredients for postCovid-19 local government development cooperation. 


\section{Section One: Introduction}

\section{Background}

In November 2019, local and regional governments, and their associations, from around the world gathered in Durban to sign a political declaration to jointly face changing global trends, and reaffirmed their commitment to 'achieving equality, diversity, universality, and...to champion the transition from an international to an interdependent interurban and solidary local governments system' (The Durban Political Declaration 2019, Point 2). The declaration situated the relevance of local and regional actors in relation to pressing contemporary issues driving global grand challenges. Just a month later, the first known cases of severe acute respiratory syndrome coronavirus 2 (SARS-CoV-2, 'Covid-19' henceforth) were identified in Wuhan, China. In the months that followed, and as Covid-19 spread worldwide, the global system has been thrown into chaos, with new and significant challenges placed on weakened infrastructures that already faced multiple and cascading pressures from rapid climate and ecological change. As local and regional actors were thrown to the forefront of immediate pandemic response, actions to foster long-term resilience too focused on local and regional innovation.

It is in this context that this study serves to update the UCLG-CIB policy paper ('Development Cooperation and Local Government', 2013). The background study will provide input for the policy paper (led by the UCLG/CIB working group) and will aim to build the case for a continued role of local and regional governments in development cooperation, and will emphasise that, globally, local governments are key actors that drive development and support decentralisation processes. Municipal and local governments are on the front lines of some of the most pressing challenges facing the global community, and more often than not, seen as leading the way towards the identification and implementation of innovative solutions. As the order of government responsible for ensuring equitable delivery of essential services, including in many cases social services around health, welfare and housing, local governments occupy an important niche in a nation's development. The study will outline how local governments actively contribute to large societal challenges and how national governments and international community can further support this work. The study will also include a focus on the role played by regional governments, for example in relation to sustainable territorial development and partnership between the different levels or orders of government, and by associations of local and/or regional governments.

The objective of the policy paper is to reflect on the current (international policy) context in which development cooperation between local and regional governments takes place, and present updated key messages, to support advocacy with local governments and their associations, and provide concrete recommendations to 
national governments and the international community and the development actors, based on the background study.

\section{Methodology and process}

As illustrated below, the study will be based on (i) a summarisation of UCLG's existing Policy Paper on Development cooperation and Local Government; (ii) a systematic desk review of relevant peer-reviewed and grey/institutional literature; (iii) a survey of UCLG members and stakeholders; (iv) follow-up interviews with key stakeholders; and (v) a workshop to co-produce lessons learned and best practices with relevant stakeholders. A CIB/UCLG reference group has provided comments, feedback, and guidance at agreed stages of the process. 
Figure 1: UCLG Priority Themes in the current global context

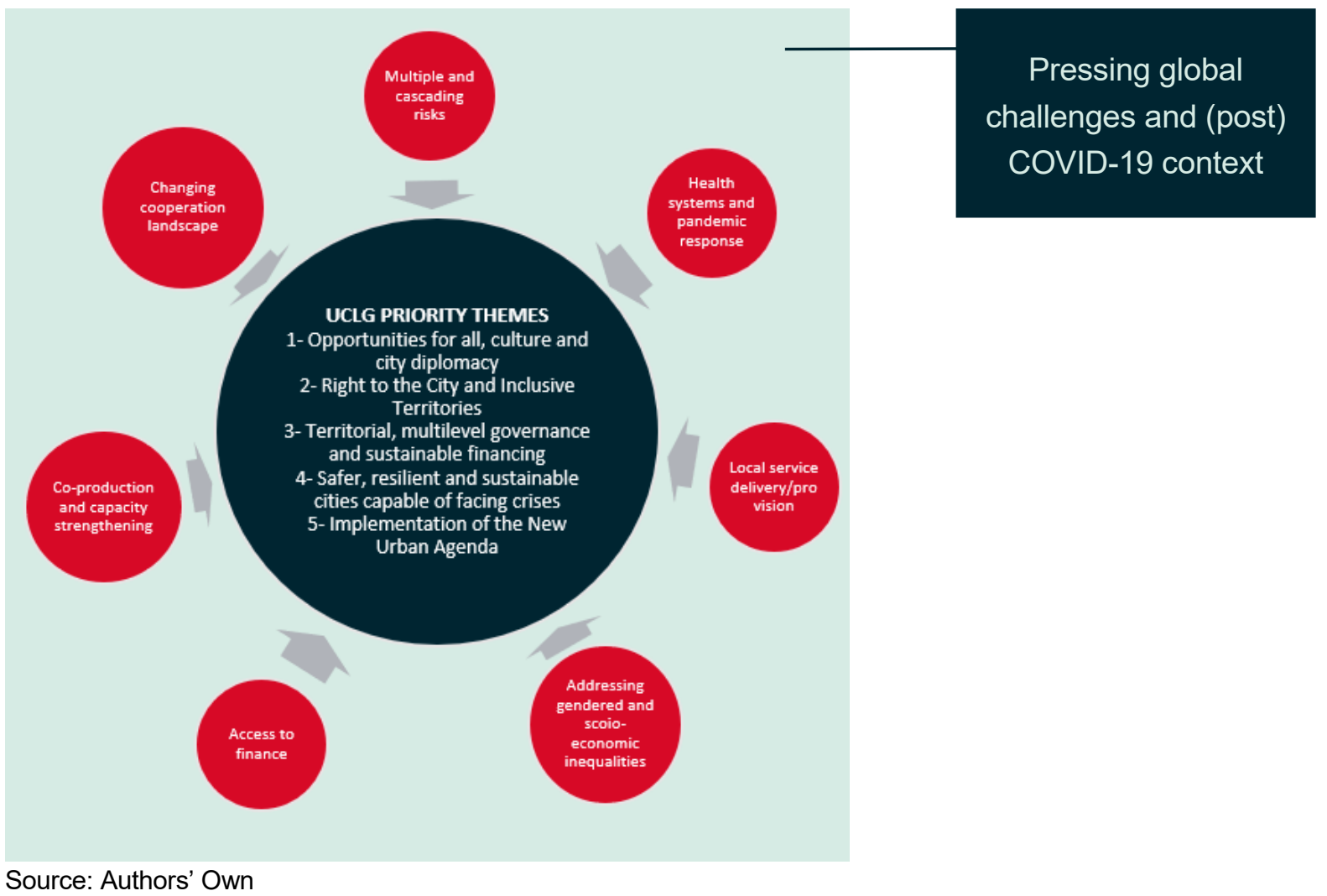

Figure 2: Methodology and study approach

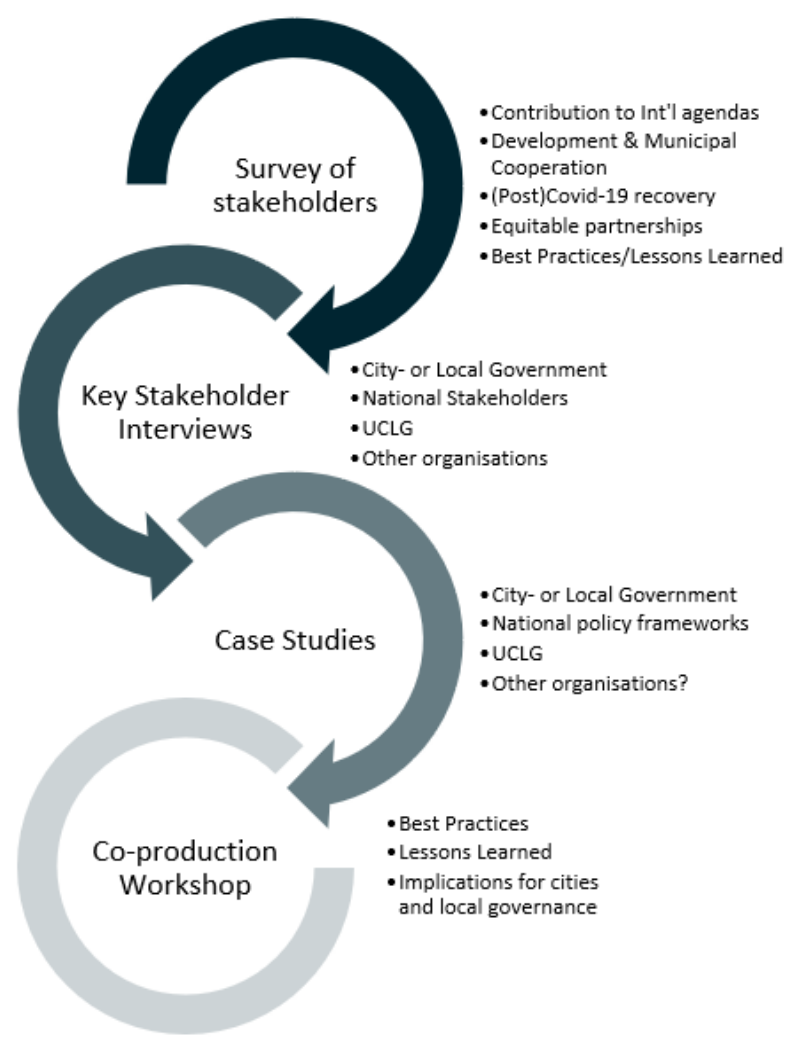

Source: Authors' Own 


\section{Achievements of decentralised cooperation to date}

Since the 1960s, links between European and North American cities as well as municipalities of Africa, Latin America, Asia, and the Middle East have existed in diverse forms. Political and environmental factors such as natural disasters, civil wars, liberation struggles, political persecution, and presence of migrant population from 'partner' countries, in particular, have played a key role in sustaining these linkages. Since the 1980s, engagements between Northern Local Governments (LGs) and Southern partners have strengthened and increased to tackle inequalities, particularly after the advent of the Millennium Development Goals (MDGs). Such partnerships have historically been diverse and have focused on (i) promoting peace and cultural dialogues, (ii) mutual learning, (iii) capacity building for LGs, (iv) enhancing trade and investment, ( $v$ ) developing strategy and partnerships for local development, (vi) tackling global issues like climate change. The role of external financing has also been crucial in supporting local development programmes and partnerships. Political will, financial means, citizen support and legal basis have been key factors particularly in Northern cities to provide funding locally. The 2008 financial crisis impacted the nature, scale, and funding of these partnerships in some Northern countries who had made contributions on their own. Aid priorities of governments also changed. For example, governments started focused on improving trade relations.

"There is an unavoidable shift taking place because of the role of emerging economies in development, and the new alliances being forged in the global South led by the BRICS and the emerging economies. We don't see it happening at programmatic level yet because the funding shift has not happened because the big funding of the $B R I C S$ is very national, and not that local. Are our programmes feeding into this new reality? Could we be working much more with local capacities? What is the new role of global North skills and capacities?" - Emilia Saiz (Interviewed on September 17, 2021)
The past two decades has seen the formation of several significant international commitments (including for example, United Nations General Assembly (UNGA) 2001 Millennium Talks; OECD's Development Assistance Committee; the biennial UN Development Cooperation Forum; the 2005 Paris Declaration on Aid Effectiveness; the 2005 Cotonou Partnership Agreement; the 2008 Accra

Agenda for Action; the 2011 Busan partnership). A review of these commitments and compacts reveals that the extent to which the international policy context has formally recognised the role of local and regional governments as actors and agents of development through international development cooperation, remained limited. Historically, their role has largely been to push national level agendas and support national and international dialogues on development. 


\section{Summary of the 2013 Policy Paper on Decentralised Cooperation}

Equality of respect in partnerships, exchange of ideas and creativity, rejection of donor-recipient paradigm and reciprocity form the core principles of LG government development cooperation. Reciprocity is value laden. It does not mean partners benefit equally as a result of cooperation but ensures partners work towards results and objectives.

The role of LGs in the delivery of essential services for improving local communities' quality of life, in capacity building of local actors, in decentralising and devolving public policies, in building linkages between civil society members, and their potential in promoting learning across LG peers were identified as key strengths of LG development cooperation.

The global trend of urbanisation leading to increased demand for services, and the international focus towards achieving development goals were highlighted as areas of opportunities for international development cooperation.

Participants also underscored the importance of developing mechanisms (in the form of capacity building of associations, strengthening of LGAs) to help develop 'voices of the South'.

Projects with little focus on results and lack of continuity due to political or administrative changes were identified as weaknesses of LG development cooperation. Threat of corruption, projects not being strategic or transferable enough; the supply-driven nature of partnerships; lack of ownership by the 'Southern' partners; lack of professional development approach such as monitoring and evaluation mechanisms; and lack of financial resources for partnerships; lack of citizen support; lack of coordination among LGs and with other stakeholders - were all identified as weaknesses of LG development cooperation.

When asked to present weaknesses as donors, participants said that adhering to donors' regulations particularly when projects are financed by donors makes accountability difficult. There is lack of financial resources for development cooperation and inadequate legal frameworks at national levels. Donors having to work with international regulations such as Paris Declaration or Accra Agenda for Legal Action recentralises public budgets which then acts as a threat to local ownership.

When asked to reflect on their practices, respondents felt that 'ownership' was being fully or partially met. The idea is that developing countries develop and implement their policies and richer partners fully support this and strengthen the capacities of partners in lower income countries. Respondents also felt that there was a risk of this being 'Northern driven' because broad strategies largely emerge from donor/funders. There exists less room for southern partners to exercise agency or 'control'. 
On mutual accountability, participants particularly those from the North felt that the donor-recipient relationship was still predominant especially in management of funds but less in execution of activities.

Mixed responses were received on the principle of harmonisation and participants felt that there should more coordination between partners ('in terms of who is doing what').

A review/stock taking of existing partnerships, largely within the domain of funding across higher income countries reveals that even though there might not be explicit recognition of LGs in international development cooperation, higher income countries do recognise LGs as development actors via international cooperation.

\section{Recommendations of the 2013 study}

Recommendations from UCLG members to tackle challenges or weaknesses of international development cooperation:

- 'Have clear focal points and goals in its programmes and systems of evaluation

- Provide tools and instruments for a public policy of LG cooperation

- Provide professional international affairs offices services of LGs or their associations

- Provide citizen education on the value of local government cooperation for development

- Develop more programme-based approaches, with clear monitoring and evaluation tools and indicators on impact

- Enhance exchange of information on projects and programmes among UCLG members, through the CIB Working Group.'

\section{How to strengthen development effectiveness?}

- Some participants also suggested that programmes rather than single city-city partnerships could lead to easier coordination, aid-effectiveness, and more effective organising and partnerships across countries.

- LGs could draw their own set of indicators to test effectiveness of LG's cooperation.

- Participants also suggested trainings that could improve capacity for management of development cooperation.

Set of recommendations for national governments and other policymakers

- Provision of support to LGs particularly in lower income countries to assist in their development cooperation activities. 
- Understand and use the added value of local government associations in lower income countries such as through provision of resources, capacity building, and including them in the planning and implementing of decentralisation processes.

- Need for stronger sustained support for South-South development cooperation particularly among countries that have undergone similar socio-economic challenges so that learnings can be shared across partners.

\section{Recommendations for local and regional governments}

- Implementation of global agendas drafted by international community needs to account for ground realities at the local level.

- Local governments are international community's critical partners in carrying forward their agenda with a sustained impact.

- Local governments must receive support and their role must be recognised in the international cooperation framework of partnerships.

- The mechanisms, tools, and methods developed by LGs and LGAs through their partnership practices are 'indispensable' for sustaining development cooperation programmes.

- Participation in LG development cooperation brings benefits to both Northern and Southern partners such as through staff professional development, public participation respectively.

- A larger coordinated programme could bring greatest impact through an agreed set of objectives for the region as well as the set of countries.

- A stronger professional approach such as through relevant training and skillsets should be exercised by LGs for development cooperation.

- There should be a clear set of shared objectives and intended results reflecting Southern partners' priorities and ownership.

- LGs to ensure political support for development cooperation activities, without being politically partisan.

- LGs should involve other partners, to widen the basis of support and participation.

- LGs should be committed to continuing improvement, learning and exchange. 


\section{Section Two: Why decentralised development cooperation matters in light of contemporary risks, challenges and opportunities}

\section{Understanding contemporary risks, challenges, and opportunities}

Amongst contemporary issues driving global grand challenges today, the study identified four as particularly relevant to decentralised cooperation, LRGs and LRGAs:

Ecological transformation and cascading risks faced by least-resourced and mostmarginalised urban and rural residents, particularly in, but not limited to, low- and middle-income countries. We have known for a while that cities are responsible for 75 per cent of global $\mathrm{CO} 2$ emissions, with transport and buildings being among the largest contributors (Araos et al. 2016). Notwithstanding, the past two decades have witnessed a 1.5 per cent annual growth in built-up areas (OECD and European Commission 2020) with many cities expanding beyond their traditional municipal boundaries. The expansion has produced complex interdependencies across denser metropolises, their surrounding commuter zones, as well as other suburban, periurban, and rural areas socially and economically linked with cities. This places women, men and children living or working in areas right across the rural-urban continuum into contact with increasingly complex risks resulting from climate change and ecological transformation, for example multiple hazards such as floods, earthquakes, landslides, volcanoes, and fires, which threaten the cyclical destruction of their lives and livelihoods, is expected to dramatically increase by 2050 (see for example UNHABITAT 2020a).

At the same time however, cities, towns and their surrounding regions are centres of opportunity and act as important hubs of economy, innovation and co-creation, production, consumption, as well as social and cultural interaction (ICLEI 2021). Assessing the prospects for effective joint action on climate change through decentralised cooperation therefore requires an understanding of the structure of the climate change problem, how this impacts livelihoods right across the rural-urban continuum, ${ }^{2}$ as well as national preferences for policy action (Keohane and Victor 2016). In particular, this requires the burgeoning transition from crisis management to multi-hazard risk-informed urban planning and decision-making. This is underscored by the Sendai Framework for Disaster Risk Reduction (DRR) 2015-2030 which

\footnotetext{
${ }^{2}$ See also UN-Habitat's The MetroHUB Toolkit available at https://unhabitat.org/topic/metropolitanmanagement
} 
identifies an urgent need for a global effort by researchers, practitioners, and governments to integrate science with action to support risk-sensitive decision making. ${ }^{3}$

Covid-19 and (Post)pandemic recovery: Covid-19 is a global challenge, but with intensified impacts in context where health and welfare infrastructure was already weakened by long standing deficiencies in financial, political and capacity constraints (Gupte and Mitlin 2021). It requires researchers, policy makers, and governments jointly address multiple dimensions which go far beyond the direct health and health systems impacts of the pandemic (Lambert et al. 2020). It comes as no surprise that a vast majority of all confirmed Covid-19 cases globally have occurred in urban areas given that the common pathogen exchange pathways and mechanisms of transmission are intensified in dense built-up environments (UN-HABITAT 2020b). While disease control has been a long-standing objective of urban planning and design (see for example McFarlane 2008), the pandemic has highlighted new questions and public debate on urban density. Initial reactions of blaming urban density for fuelling the pandemic have shifted to 'a more nuanced geographical understanding of the pandemic and its urban dimensions, focused less on densitiesat-large and more on particular spatial connections and conditions' (McFarlane forthcoming: 7).

The key challenges for local and regional governments, and the decentralised cooperation agenda, rest on the longer-term and broader health-systems implications, as articulated by CIBs position paper on Covid-19, ${ }^{4}$ and in their responsibilities in raising awareness around robust scientific evidence, in providing key infrastructure and services, as well as in building collaborative partnerships with sub-municipal, national, regional, and international actors.

\section{Gendered and socio-economic inequalities in accessing basic services and} infrastructures: the world is facing a $\$ 15$ trillion infrastructure gap by 2040 . One in three people globally do have access to safe drinking water and sanitation, while over half of the world's population do not have access to adequate and affordable health services. In cities and towns, close to one billion people live and work in informal, under-serviced, and precarious urban conditions worldwide, while billions more rely on patchy and unreliable piped water, electricity, and health-care access in cities with deteriorating infrastructures. Furthermore, and as recent experiences of Covid-19 have shown, inequalities in access to infrastructure and services are deeply gendered (Holmes 2021). Even before the crisis, women were already more likely than men to live in poverty, to work in lower-paid and insecure employment, and to lack access to

\footnotetext{
${ }^{3}$ See United Nations Office for Disaster Risk Reduction, UNDRR Sendai Framework for Disaster Risk Reduction 2015-2030 (2015)

${ }^{4}$ See https://www.cib-uclg.org/tags/covid-19
} 
formal social protection (SP), savings and financial services (UN Women and WHO 2020).

A multi-pronged approach to reducing the infrastructure gap is required to counter an unfettered trend for national infrastructure building or renewal which increases demand for resources, often in unsustainable ways (see for example Pelling et al. 2021). LRGs share key responsibilities with national governments in meeting the infrastructural gap through building new assets or retrofitting existing infrastructure, optimising access, as well as reducing demand for new infrastructures. ${ }^{5}$ In particular, the responsibilities of local governments encapsulate enabling public services and agents responsible for education, health and housing policies, and protectors of rights, regardless of peoples' gender or legal status. Furthermore, LRGs and LRGAs face the challenge of redistributing the allocation of funding for public urban infrastructure through various socio-spatial (targeting disadvantaged areas or populations), systemic (addressing issues such as centralisation), or structural (transforming funding allocation and delivery systems) redistribution strategies (Wiesel and Liu 2021).

Accessing Green Finance: Related to the challenge of addressing the infrastructural gap, LRGs and LRGAs face the significant challenge of achieving sustainable development through financing or refinancing new and existing public and private investments that explicitly have environmental objectives. 'Green finance', 'climate finance' or 'adaptation finance' includes new and additional public finance from global North to South, or more widely any expenditure on climate change mitigation and adaptation (as defined by Buchner et al. 2014), as well as resources committed to support resilience and adaptation activities in the global South. ${ }^{6}$ There are significant challenges and barrier to directing international climate finance through and to locallevel organisations. Colenbrander, Dodman, and Mitlin (2018) summarise these as arising because such finance is primarily allocated to multilateral entities and national governments, rather than local organisations. Sub-national governments and civil society, particularly from the global south are excluded from national and institutional decision-making processes, while donors often prefer large-scale heavy infrastructure projects to reduce transactions costs associated with projects at smaller scales (Colenbrander et al. 2018: 906).

Several collaborative and cooperation initiatives are already driving urban climate action for mitigation and adaptation (for example, the Global Covenant of Mayors (GCoM) is the largest network of cities with this objective). The challenge in the coming decade is to move from planning to implementation, and more specifically to

\footnotetext{
${ }^{5}$ See Strategic Infrastructure: Steps to Prepare and Accelerate Public-Private Partnerships. May, 2013. Geneva: World Economic Forum. http://reports.weforum.org/strategic-infrastructure-2014/introduction-theoperations-and-maintenance-om-imperative/the-global-infrastructure-gap/\#view/fn-10

${ }^{6}$ For example, as part of the UNFCCC process, and disbursed through multilateral climate funds including the Green Climate Fund, Adaptation Fund, Least Developed Countries Fund, Climate Investment Funds, Strategic Climate Fund, Global Facility for Disaster Reduction and Recovery and Pilot Program for Climate Resilience, among others.
} 
unlock climate finance at the local level. This involves enabling partners and facilitating dialogue with private sector and finance institutions, linking cities with relevant cityscale initiatives for funding, facilitating inter-government dialogue on climate finance, as well as co-ordinating action between national and international commitments contributing to the SDGs (see ICLEI 2021).

\section{Current state of decentralised cooperation}

\section{Scholastic advancements:}

'Global' urban agenda and the state of city-networks: Local and global planning practices are in constant interaction, influencing each other in ways that are shaped by power relationships, spaces of knowledge circulation, institutions, and politics at international and local level (Cociña et al. 2019). Much has been achieved since the first United Nations Conferences on Housing and Sustainable Urban Development (Habitat I) to speak of a 'global' urban agenda as
"[In the early 1990s] it was not natural to talk about migration and LGs, about capacity building of human resources, about service provision within international development. People were talking about governments in general, but not empowering local governments as true political actors. We need to recognise this achievement because the new topics that we have been able to bring in the agenda will make it or break it in sustainability debate, in achieving the SDGs. I think we have been able to scale up because we have inspired national development plans. And we have inspired political changes in constitutions around the world. I do think we have been able to speed up the process." - Emilia Saiz (Interviewed on September 17, 2021).

articulated in compacts such as the Sustainable Development Goals (SDGs). We have an array of urban-relevant global initiatives operating in the urgency of the final decade of the 2030 Agenda that are moving to key milestones and commitments in the New Urban Agenda (cities, localisation), such as the Paris Agreement (on climate change and Net Zero), the Sendai framework (on risk reduction and resilience), the Addis agenda (on local finance) and the Beijing declaration (on gender). Cities are also attracting the attention of major international actors, with city leaders pivotal to global governance (Acuto 2013), regularly featuring as part of multilateral processes (Acuto et al. 2016). At the city-level, there has been a 'networking boom' with hundreds of city-networks forming every year (Acuto and Rayner 2016).

To get a sense of the trajectory of 'decentralised cooperation' as a scholarly concept, we systematically reviewed all published literature using Web of Science. The appropriate search syntax ${ }^{7}$ identified 479 studies published since 1991, with more than half published in the past five years, an average citation count of 10.56 per study, and an h-index of $31^{8}$. Of these, 206 studies were identified as partially or completely

\footnotetext{
${ }^{7}$ Web of Science search syntax used: $\left(A L L=(\right.$ decentrali* $A N D$ (cooperation OR co-operation)) $) A N D\left(A L L=\left(\right.\right.$ govern ${ }^{*}$ AND (municipal* OR local OR urban OR city OR suburban OR metropolitan OR "peri urban" OR regional))).

8 The $h$-index value is based on a list of publications ranked in descending order by the times cited count. An index of $h$ means that there are $h$ papers that have each been cited at least $h$ times.
} 
focussed on Development Assistance Committee listed low- or middle-income aid recipient countries. The first studies identified were published in the early 1990s. Since then, there has been a significant rise in the number of studies published, as well as the number of citations received by these studies, in the early 2000 s.

It is interesting to juxtapose the publication and citation trajectory of this literature alongside the development of decentralised cooperation: 1992 marked the year in which local authorities were globally recognised as key actors in sustainable development through 'Agenda 21'. Then in 1995, the formation of the Commonwealth Local Government Forum (CLGF) triggered the need to focus on local democracy amongst Commonwealth countries. In the same year, development cooperation experienced efforts by global networks such as Local Governments for Sustainability (ICLEI) on the environment and climate action agenda. ICLEI in the United States (US), for example, managed to consolidate a network of cities, towns, and counties to achieve reductions in greenhouse gas emissions. In this period, the UN Habitat II conference was instrumental in shaping governments' understanding about the role of local authorities. Governments in this conference recognised the need for capacity building of local authorities and identified them as key 'partners' in development. In early 2000s with the formation of UCLG, the role and influence of local and regional authorities in democratic governance was highlighted at the global level. A key moment in decentralised cooperation took place in 2004 when a cooperation agreement was signed between UN-Habitat and the local government movement to promote the adoption of international policies on decentralisation. The setting up of the GOLD was the first stocktaking exercise that captured the state of decentralisation at the global level. In the current decade, various shifts have taken place in the landscape of decentralised cooperation. More conferences have been organised and various thematic areas have been pushed forward in global agendas (such as the role of local actors in water and sanitation projects, slum upgrading, etc). The UCLG World Congress held in 2013 aimed at defining a roadmap of local governments towards the New Development Agenda. The Habitat III conference held in 2016 provided local and regional governments with a platform to debate and define key topics including governance, local democracy, well-being, diversity, and solidarity. More recently, the localisation of the SDGs has been a key tool in defining how many cities and local government actors are involved and connected in this global landscape of decentralised cooperation.

The graph below charts the number of publications and the number of citations along a timeline of significant global decentralised cooperation events: 
Figure 3: Number of publications and citations on 'decentralised cooperation and local government' increased significantly after 2004, and again after 2007

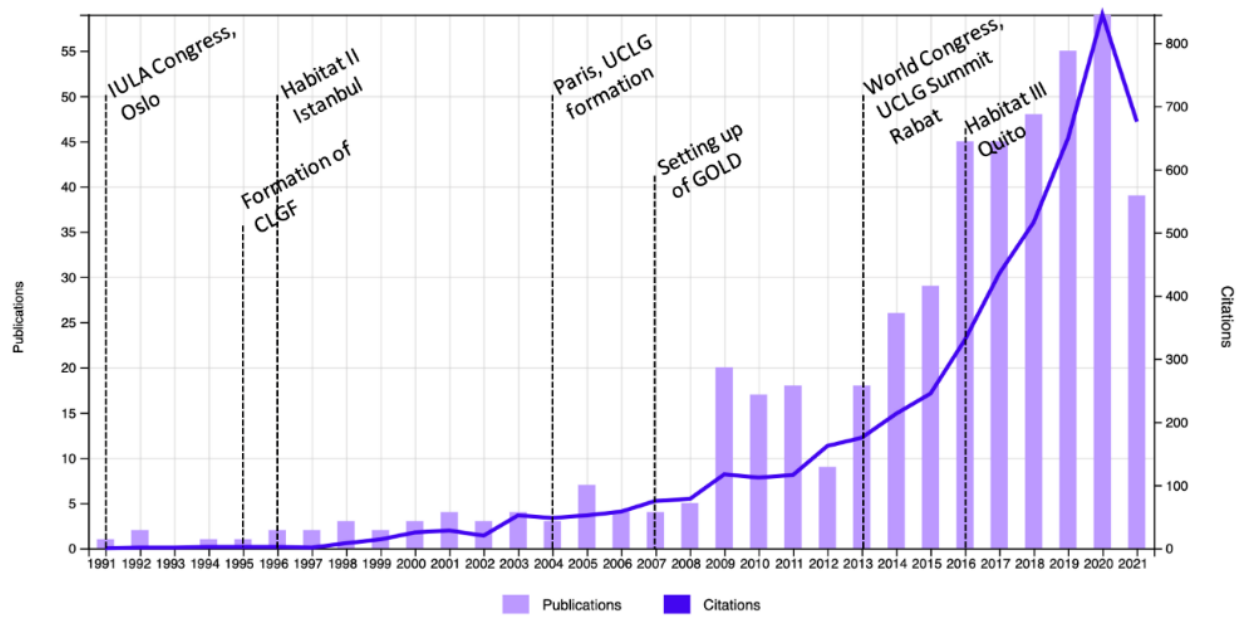

Source: based on data from Web of Science

The tree-maps below illustrate the 479 studies identified in the systematic search by academic disciplines or research and by funding agency, where these are easily identifiable. Expectedly, Environmental studies/sciences, Economics, Public Administration, Regional urban planning, Political Science, Geography, Development Studies, and Urban Studies are the disciplines or research areas where most of the research activities are located. Amongst the most prominent funding agencies ${ }^{9}$ are the European Commission, including the Joint Research Centre, the National Natural Science Foundation of China, the Consultative Group on International Agricultural Research (CGIAR), the National Science Foundation (NSF), the Spanish Government, the SDC, the Swedish Research Council, UK Research and Innovation (UKRI), and the United States Agency for International Development (USAID). Multi-lateral banks like the World Bank, Deutsche Bank, Interamerican Development Bank, and Nordea Bank Fund have also funded a selection of studies, as have a number of private and other foundations, including: Bill and Melinda Gates Foundation, the Mistra Swedish Foundation for Strategic Environmental Research, the Arcus Foundation, the BBVA Foundation, the Enel Foundation, the General Electric Foundation, the Getulio Vargas Foundation, the Ford Foundation, the John D And Catherine T Macarthur Foundation, the Wellcome Trust, the Volkswagen Foundation, and the Open Society Foundation. Alongside these funding agencies, trusts and foundations, it is important to note that a long list of universities and higher-education institutions have also directly funded research on decentralised cooperation.

\footnotetext{
${ }^{9}$ It is important to note that the count of studies funded does not take into account the amount, duration or share (where there maybe more than one funding agency) of funding. Some funding agencies may be underrepresented due to accrediting authors using varying names or acronyms, or due to the change in name of agency. For full list of funders please contact the UCLG CIB Working Group uclg.cib@vng.nl.
} 
Figure 4: Tree-maps illustrating 479 studies identified by academic disciplines, or research and by funding agency.

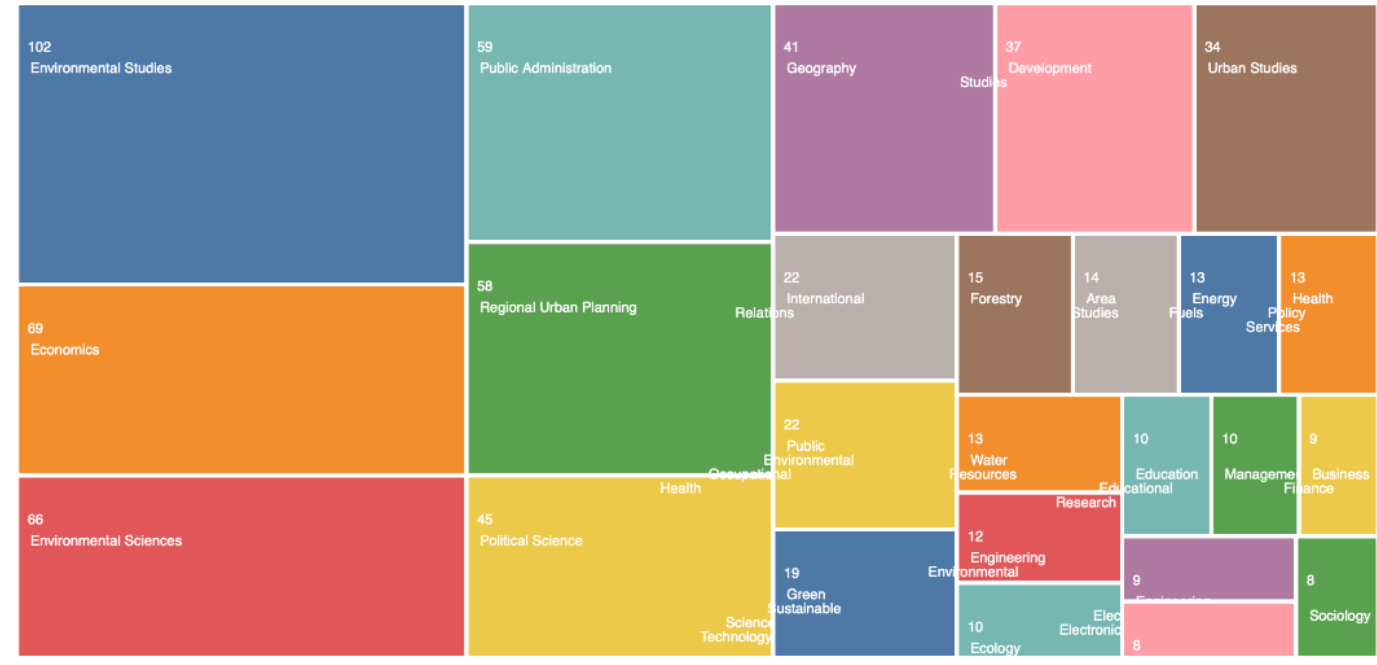

Source: based on data from Web of Science

Table 1: Lead academic disciplines or research areas and prominent funding agencies, where identifiable, for published studies on decentralised cooperation

\begin{tabular}{|c|}
\hline Prominent Governmental and Other Funding Agencies \\
\hline European Commission (including Joint Research Centre) \\
\hline National Natural Science Foundation of China (NSFC) \\
\hline Consultative Group on International Agricultural Research (CGIAR) \\
\hline National Science Foundation (NSF) \\
\hline Spanish Government \\
\hline Swiss Agency for Development and Cooperation (SDC) \\
\hline Swedish Research Council \\
\hline UK Department for International Development (DFID) \\
\hline UK Research and Innovation (UKRI) \\
\hline United States Agency for International Development (USAID) \\
\hline Australian Research Council \\
\hline German Research Foundation (DFG) \\
\hline Netherlands Organization for Scientific Research (NWO) \\
\hline Norwegian Agency for Development Cooperation \\
\hline Swiss National Science Foundation (SNSF) \\
\hline Australian Agency for International Development (DFAT) \\
\hline Generalitat De Catalunya \\
\hline Swedish International Development Cooperation Agency (SIDA) \\
\hline Catalan Institution for Research and Advanced Studies (ICREA) \\
\hline Deutsche Gesellschaft Für Internationale Zusammenarbeit (GIZ) \\
\hline
\end{tabular}

Source: based on data from Web of Science 
This illustrates an important trend in the scholastic effort devoted to decentralised cooperation. Scholastic interest has consolidated alongside global, regional, and local initiatives that have increasingly and in more nuanced ways applied decentralised cooperation as a central tenet in achieving the Sustainable Development Goals. In addition, we also identified a vast and growing literature on service provision involving local or regional governments and authorities to assess the extent and nature of impact LRGs have on people's everyday lives. Through a systematic literature search, we identified 1,065 studies published in peer-reviewed publications since 2016 (last five years). Of these, 281 studies have above average citation counts, ${ }^{10}$ and 116 studies were specifically on Low- or Middle-income countries. We summarise these literatures in the sections below:

\section{Growing consensus on defining decentralised cooperation}

Decentralised cooperation has its roots in the field of international relations where 'municipal twinnings' are a mode of international relationships (Hafteck 2003). This understanding was greatly expanded with the recognition of the role of partners from developing countries or those in transition. There is a new and growing consensus that local and regional governments have a strategic role to play in the implementation of the 2030 Agenda (Krukowska-Siembida 2020). 'These actors, through decentralised South-South cooperation and triangular cooperation, take on special relevance both in multi-level planning and in the execution of public policies aimed at the implementation of the Sustainable Development Goals in their territories' (Ojeda Medina 2020: 9).

$\rightarrow$ For this study, 'decentralised cooperation' is defined as a set of collaborative, multi-scalar, translocal and transnational relationships between local governments and their associations (Agranoff 2014), with the objectives of improving local government performance in terms of administration, service delivery and level of responsiveness to community needs, while simultaneously encouraging citizenship and citizen participation in urban decision-making (Bontenbal 2009). These objectives are local or regional expressions for achieving global sustainable development (Amis 2013; Guha and Chakrabarti 2019), which are therefore shaped by and include responses to contemporary global challenges in a number of administrative, procedural, and geo-political ways.

International development assistance and aid remain the main instruments in driving the international development cooperation agenda. The High-Level Forum On Aid Effectiveness (HLF-4) hosted in Busan in 2011 marked the third expansion wave in international cooperation by shifting the global agenda from aid effectiveness to development effectiveness (Li et al. 2018). Through its formation of the Global Partnership for Effective Development Co-operation (GPEDC) platform, the HLF-4

\footnotetext{
${ }^{10}$ Cited at least 4 separate times, and not by self
} 
sought to increase the voices of multiple stakeholders, particularly those from the South. There is a view that the Development Assistance Committee (DAC) of the OECD remains a key actor in setting the procedures, instruments, and mechanisms for monitoring the effectiveness of development interventions. As a result, China and other emerging economies have not actively engaged with the GPEDC platform. However, there seems to be continued efforts in developing new frameworks for South-South cooperation. Such triangular frameworks include Africa-China-UK, AfricaChina-USA, Africa-China-Bill and Melinda Gates Foundation cooperation. The GPEDC, nonetheless, has created momentum for Southern players to participate in development cooperation and play a role in the governance of dev cooperation but challenges remain when it comes to operationalising GPEDC (Li et al. 2018).

\section{City to city learning*}

\begin{tabular}{|c|c|c|}
\hline Region, focus country & Levels of governance & Funded by \\
\hline $\begin{array}{l}\text { South Africa, Mozambique, } \\
\text { Barcelona }\end{array}$ & Municipal, National, Sub-municipal & City of Barcelona \\
\hline \multicolumn{3}{|c|}{$\begin{array}{l}\text { Description Bi-lateral city-to-city projects between the city of Barcelona and the municipalities of Maputo } \\
\text { have allowed for the exchange of city-city experiences in municipal management and local governance. } \\
\text { Barcelona's efforts at strengthening North-South relationships has fostered exchange of knowledge, } \\
\text { objectives and visions across North-South geographies. In particular, this form of collaboration goes beyono } \\
\text { an institutional relationship between two municipal governments and involves specific involvement of many } \\
\text { government departments. }\end{array}$} \\
\hline
\end{tabular}

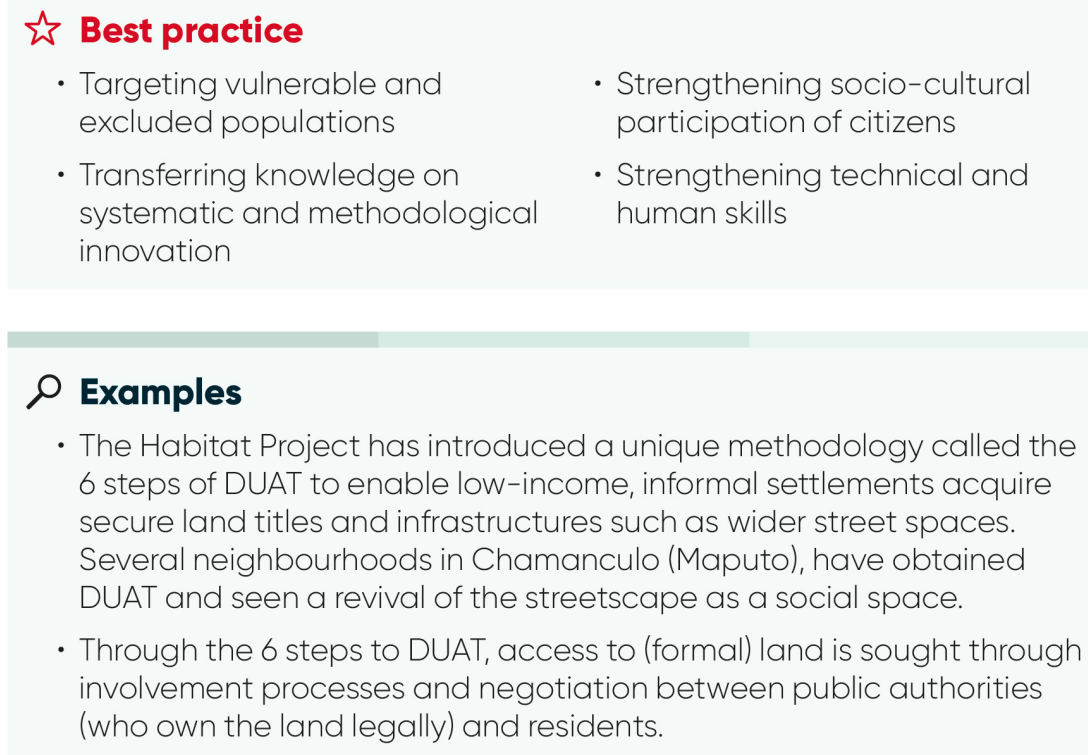

\section{O Examples}

- The Habitat Project has introduced a unique methodology called the 6 steps of DUAT to enable low-income, informal settlements acquire secure land titles and infrastructures such as wider street spaces. Several neighbourhoods in Chamanculo (Maputo), have obtained DUAT and seen a revival of the streetscape as a social space.

- Through the 6 steps to DUAT, access to (formal) land is sought through involvement processes and negotiation between public authorities (who own the land legally) and residents. 
The rise of the South, and financial and economic uncertainties faced by OCED countries, and increasing urbanisation, development cooperation has tended to move away from the normative 'North to South' aid-driven framework. Development cooperation has come to be more focused on collaborative partnerships, human and institutional capacity building built through an exchange of expertise, technology and experiences (Nganje 2015) . Although a number of North-South decentralised cooperation programmes have been initiated, there still exists a dissimilarity in the institutional, historic, and socio-economic contexts of the North and the South, and therefore in the networks of decentralised cooperation in these contexts. It is in this context that decentralised South-South cooperation, has emerged as an approach to promote sustainable development and capacity building in the South. The potential of decentralised cooperation in promoting peace is also recognised in conflict-affected settings. Institutional capacity strengthening of local authorities or by stimulating healthy state-society relations by provision of technical, financial, material and moral support to local authorities are some instruments that could promote peace (Nganje 2015).

\section{Decentralised cooperation for peacebuilding in fragile contexts*}

\begin{tabular}{lll} 
Region, focus country & Levels of governance & Funded by \\
Middle East, Lebanon & $\begin{array}{l}\text { National, Municipal, } \\
\text { Sub-municipal }\end{array}$ & Municipality of Arsal \\
\hline
\end{tabular}

Description To secure peace in the city, the municipality of Arsal has been at the forefront of creating opportunities for social cohesion, particularly between different communities residing informally. It has organised interventions to facilitate different groups who may be equally vulnerable to conflict.

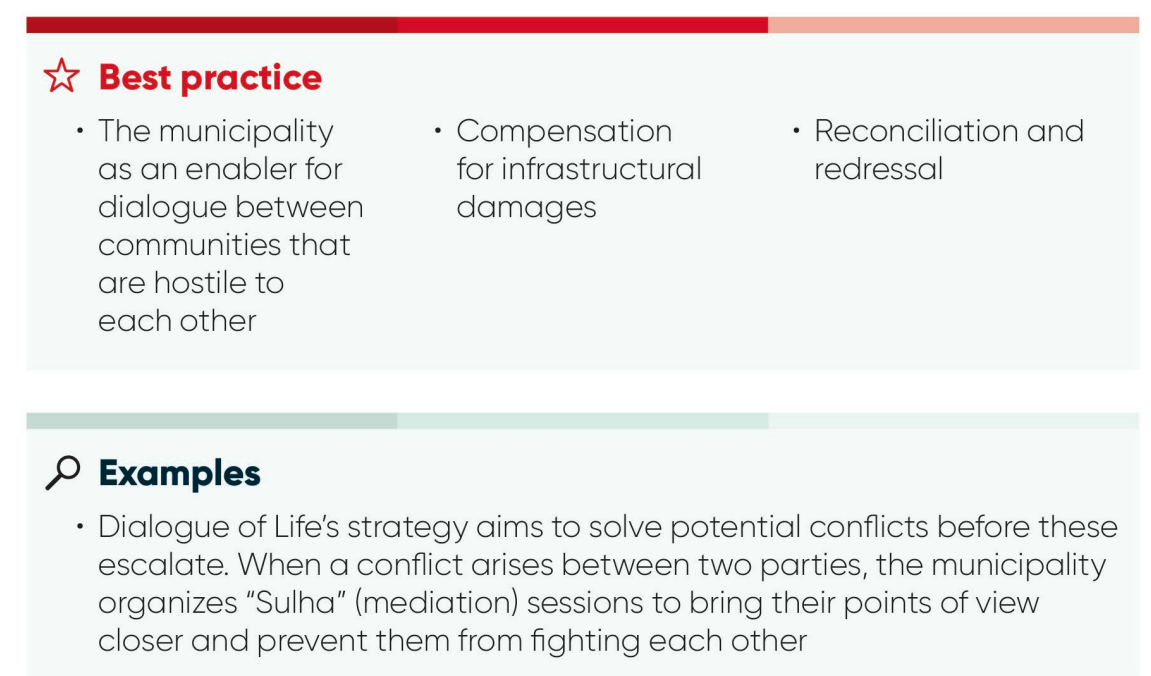


Cultural diversity continues as an important source of knowledge, a vital element of citizenship, and as a component for peaceful resolution of conflicts. Cultural cooperation is also the vehicle to heal the consequences of colonialism and to decrease of the high levels of inequality. Cities and local regions are not only important platforms on which cultural diversity and heritage is celebrated, they also present opportunities for intercultural responses to development challenges, and in conflictaffected settings have the potential to contribute to peacebuilding through institutional capacity strengthening of local authorities or (UNU-CPR 2015). In the context of contemporary global challenges, 'transformation' of development cooperation can also be conceptually viewed as going 'beyond aid' and as an umbrella term that includes four key dimensions - actors, finance, regulation, and knowledge (Janus, Klingebiel and Paulo 2015) - that help identify potential synergies between development cooperation and socio-cultural responses to global challenges. This reduces a transactional focus on aid itself, and moves us towards other areas or forms of learning such as indigenous knowledge and integration of local capacities. It is important to note that in this conceptualisation, actors include a variety of organisations (local, international, non-governmental organisations (NGO)-based, charities), ministries, cities, and forms of partnerships that allow greater choice and more competition between donors. 


\section{Intercultural and heritage responses to development challenges through VLRs*}

\begin{tabular}{lll} 
Region, focus country & Levels of governance & Funded by \\
Global & National (national associations), Regional & $\begin{array}{l}\text { Various institutions and } \\
\text { governments }\end{array}$ \\
\hline
\end{tabular}

Description Since the First World Public Meeting on Culture in 2002 and the approval of Agenda 21 for Culture in 2004, LRGs and LRGAs have increasingly placed a cultural dimension within their public policies responding to developmental challenges. LRGAs have collaborated to advocate cultural and heritage rights operationalise their intercultural and heritage rights policies.

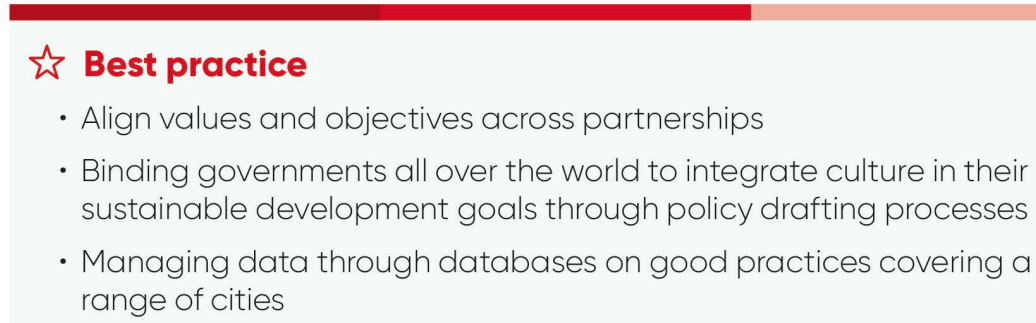

\section{O Examples}

- The United Cities and Local Governments (UCLG), the International Council on Monuments and Sites (ICOMOS), the International Federation of Library Associations and Institutions (IFLA), the International Federation of Coalitions for Cultural Diversity (IFCCD), and the Culture Action Europe collaborate to produce the Culture 2030 Goal Campaign report

- UCLG prioritises culture in sustainable development by forming the Culture Committee

- International Council on Monuments and Sites (ICOMOS) has been working on the integration of culture and heritage into a range of development issues such as sustainable urban-rural development, tourism, climate action, and disaster preparedness

- International Federation of Library Associations and Institutions (IFLA) has continued its mission of advocating for libraries to support individuals and societies with the right to information

- Culture Action Europe has focused on advancing local and European understanding of the connection between culture and local development in cities

Although competition promotes innovation and new models of cooperation, proliferation of actors could also lead to coordination problems, and lack of data and information relating to scope and nature of development activities. Finance is conceptualised differently from aid. It captures the proliferation of the sources and mechanisms of raising finance locally or from a country's own resources. ${ }^{11}$ Public-

\footnotetext{
${ }^{11}$ A large proportion of development finance in Africa, for example, has been raised through the national tax revenues in comparison to foreign aid (Atisophon et al., 2011).
} 
private partnerships are more innovative sources of finance that raise funds privately but remain tied to development goals. Regulation refers to national policy frameworks and international regimes such as migration policy, international trade regime, climate, and security rather than soft rules or processes that are merely mechanisms responsible for transferring or implementing aid. Knowledge relates to the sharing of scientific and technical expertise across a range of actors and regions. In the beyond aid framing, the challenge then, is to identify and share knowledge that not only applies to different contexts but is also specialised (Janus et al. 2015).

Knowledge creation too has been a critical dimension of continued relationships between donors and recipients in the process of receiving aid. The cases of China, Indonesia, Japan and Thailand depict that new forms of knowledge are created through continuous interaction with donors, combining foreign knowledge with local knowledge, tacit and explicit knowledge. South-South Cooperation (SSC) from these countries show that the acquired knowledge is distributed around the developing world through technical and financial cooperation (Shimomura and Ping 2018). The role of emerging economies in advancing the international cooperation agenda has also been emphasised (see IDS Bulletin, 2018). The last decade has seen an evolving global development landscape with the centre of gravity emerging from the global South. New processes and practices, international dialogues, multilateral institutions and agencies, cooperative agreements have come to the fore. China as well as other emerging economies are being seen as critical players (Gu and Kitano 2018). Amidst this changing global dynamics, new avenues have opened up for South-South Cooperation including the growing influence of emerging countries such as Brazil, Russia, India, China and South Africa (BRICS). In particular, scholars have argued that emerging economies can be important drivers for disaster risk reduction and promotion of processes underpinning South-South cooperation (Renwick 2018). They can for instance, provide critical insights and practical experience to other economies that face similar environmental challenges. Although emerging economies can be highly diverse, when viewed as a 'collective grouping', they can offer common principles, perspectives and approaches to sustainable development, climate change adaptation and disaster risk reduction. The role of these economies as both recipients and providers of international development assistance, humanitarian aid and disaster relief can offer rich experiences for South-South cooperation which is distinctive yet evolving. Mexico's exemplary experience with DRR provides learnings for DRR cooperation at national, regional, and global levels through its story of multistakeholder engagement for economies that experience natural disasters (Renwick 2018).

\section{Local service provision and decentralised cooperation}

Understanding governance issues at the local level is critical for achieving the SDGs where delivery in most contexts is mediated by local actors, public and private institutions, and both local and international processes. For example, building on case studies in India, Mexico, Tanzania, Ghana, and Kenya, Herrara (2019) underscores 
local-level complexities in the delivery of water and sanitation which is largely undertaken by local actors (citizens, public utilities, private sector) and local governments instead of federal governments which largely liaise with international partners for monitoring and evaluation. She finds that politics of patronage at the community level, elite capture through privatisation, politicisation of public utilities, diversion of resources and infrastructures for political reasons, lack of investment in human capital development, high turnover of employees in service delivery institutions, as well as lack of regulatory mechanisms coupled with lack of participatory approaches involving local communities in decision making hinder implementation of water and sanitation delivery.

Similarly, the contracting-out of healthcare services by local government institutions such as City Councils or Municipalities to non-state providers such as NGOs in urban centres is complex and contingent upon a set of political, institutional and governance factors interfacing with the country's health system (see among others Joseph and Maluka 2016; Zon et al. 2017; Stephen et al. 2018). For example, Islam et al. (2018) develop this claim by underscoring that the contracting out process in a large scale health programme is subject to (i) political motivations and rivalries which influence the involvement of municipalities in becoming direct providers as opposed to contracting it out to NGOs, the selection of particular NGOs, managerial powers at the city level, (ii) local politics which also influences the decisions undertaken by municipalities regarding areas that would be provided with healthcare services, (iii) expertise and interest of local government institutions in the delivery of healthcare service which in turn affects achieving project deliverables and participation in meetings, (iv) the external environment, for example, donors' interests influence project strategies, (v) technical capacities of LGIs which is critical in rolling out the contracting process, (vi) sustained relationships between LGIs and NGOs which need to be based on mutual trust and there needs to be greater participation/involvement of NGOs in preparing contracting documents.

\section{Evolution of networks for decentralised cooperation and their contribution to global agendas}

For the purposes of this paper, it is important to consider how the role of LGRAs has evolved. As one of the leading global networks of local authorities, United Cities and Local Governments UCLG's role is indicative of the broader movement around localising development cooperation, and therefore of the growing role for networks to bring together regional and local authorities on a transnational platform. The World Assembly of Local Authorities is in many ways the contemporary space for local and regional governments, and their members and how they meet. The UN and the World Assembly of Local Authorities have recognised UCLG in its roles particularly with respect to New Urban Agenda, ${ }^{12}$ and it is important to note that this has in part created

12 Interview with (Emilia Saiz, September 17, 2021 ; Aromar Revi; March 26, 2021) 
space for local actors representing smaller or secondary cities, towns and regions on transnational platforms that hitherto had been dominated by authorities representing mega-city or regions. At the same time, there has been a noticeable shift of some mayors towards networks such as C40 that were explicitly set up to bring together the world's largest and most resourced cities. ${ }^{13}$

"One of the strategic challenges for LRGAs since Habitat III has been to showcase the effectiveness of opening up the transnational cooperation space to a wider set of LRGs and civil society organisations without adversely impacting the overall theory of international governance. This requires a neat organisation of international cooperation theory with international cooperation practice. The Global Task Force is one way to organise such partnerships." Aromar Revi (Interviewed on March 26, 2021).
Advocacy as an objective and as a method is playing an increasingly important role across LRGAs of various sizes. ${ }^{14}$ The United Nations Conference on Housing and Sustainable Urban Development (Habitat III, Quito October 2016) prioritised an increasing connection between local and regional authorities and civil society members. There was acknowledgment at the global

level about the significance of the local and formulation of lateral alliances. The conference also saw UCLG respond by bringing community- and grassrootsorganisations closer to their LRG members and to their objectives for achieving the Sustainable Development Goals. ${ }^{15}$

The past decade has seen the formation and maturation of a range of urban-relevant global initiatives, all operating in the urgency of the final decade of the 2030 Agenda. Of note are the New Urban Agenda (with a focus on cities, human settlements, and localisation), the Paris Agreement (with a focus on climate change and Net Zero), the Sendai framework (with a focus on risk reduction and resilience), the Addis agenda (with a focus on local finance) and the Beijing declaration (with a focus on gender). With LRGs central to the objective setting as well as the delivery of these global compacts, LRGAs have had to organise themselves to support and facilitate action in line with the compacts.

A key space in this regard is the Global Task Force (GTF), created by UCLG in 2013. The GTF continues to ensure the coordination of and communication across the task force members. It is a unique space for dialogue, exchange and strategising as there are not many spaces like these for the membership. It brings together networks like C40 , UCLG, or ICLEI, in the least to set forth and discuss minimum common strategies, as well as to think of how to qualitatively link with the UN system, and global community. The stakeholders interviewed for this study felt it important to point out that the GTF is sustained through a notion of solidarity of a united voice of the

\footnotetext{
${ }^{13}$ The 97 C40 affiliated cities account for $25 \%$ of global GDP. See https://www.c40.org/cities

14 Interview with Edgardo Bilsky, March 26, 2021

15 Interview with Jean-Baptiste Buffet, March 26, 2021
} 
constituencies. This was a major shift from previous ways of organising in relation to $\mathrm{UN}$ actors for example. Furthermore, the organisation operates through content collaboration, nurturing partnerships, and high-quality policy and political debates, in a structural way.

Another important aspect of localising development cooperation has been the multilayered nature of decentralised actors. For example, decentralised cooperation involves relationships between LRGs, their associations or networks, and networks of networks or associations. An important example is Platforma, ${ }^{16}$ with their main partner the Council of European Municipalities and Regions (CEMR). Platforma works on several thematic issues ranging from development effectiveness, sustainable finance for development, amongst others. There is also a close exchange of work between the CIB of the UCLG and Platforma's working group. In describing this multi-layered nature of decentralised cooperation, a key stakeholder highlighted that 'there is a healthy sharing of interests and responsibilities with UCLG showing a committed interest and involvement in European debates, whilst Platforma is increasingly drawn on and contribute to global issues and debates'. ${ }^{17}$

"The social agenda is relatively stronger within UCLG [as compared with other spaces or networks for decentralised cooperation]. What is more challenging is that this is still very focused on the developing world, but less attention has been paid towards developmental and societal challenges in the global North, particularly in ways that speak to, for example, the financiers in European countries. Networks such as the C40 draw a much heavier involvement from the largest and well-resourced cities, but not being a central part of such a space, UCLG misses the opportunity of influencing a global conversation" - Elena Pierce, (Interviewed on April 9, 2021)
On environmental issues, UCLG shares the space with key LRGAs like ICLEI and C40 which are more active on environmental issues and climate change agenda. In the framework of global task force UCLG is a leader on Agenda 2030 , and on key issues such as gender equality, the debate on finances with international agencies, multilateralism, culture, and disaster risk reduction. ${ }^{18}$ It is also leading the debate on the role of international institutions and is a

key actor in the Global Parliament of Mayors (supported by the EU). At the international level, there has been a conscious effort to bridge these various agendas and priorities across LRGAs. For example, the Commission on the Status of Women, UCLG and stakeholders across the global community put together a statement where they found local governments could fit into the policy agenda. ${ }^{19}$

\footnotetext{
16 See https://platforma-dev.eu/who-we-are/

17 Interview with Amandine Sabourin and Sarah Bentz, April 1, 2021

18 Interviews with Jean-Baptiste Buffet, March 26, 2021 and Edgardo Bilsky, March 26, 2021

19 Interview with Emilia Saiz, September 17, 2021
} 


\section{Creating space for women in urban science and practice*}

$\begin{array}{lll}\text { Region, focus country } & \text { Levels of governance } & \text { Funded by } \\ \text { UCLG Africa, Africa \& Europe } & \text { Municipal, National, Regional } & \text { Various governments \& international bodies }\end{array}$

Description Ensuring women's participation in local decision-making processes and enabling equal representation in social, political and economic domains have been key areas of work for LRGs, LRGAs and their constituencies. Mentoring is being adopted as a pathway for equal participation of women in urban science and urban practice. Through the REFELA network, UCLGA brings together African women mayors and locally elected representatives for gender sensitive local governance. This approach is grounded in strong advocacy within national governments and political parties. Using SDG 5.5.1b goal as its guiding pillar, the Commonwealth Women in Local Government Network through CLGF has adopted a transformative feminist mentorship approach to build leadership capacities of women who are already elected, and raise participation of women who are aspiring to hold public office.

\section{is Best practice}

- One-on-one mentoring sessions and consultations with mentors and mentees

- Experiential / hands-on learning
- Forming of women's networks and alliances through collaborative learning

- Conducting trainings (designed) by local governments, associations, and political parties

\section{$\triangle$ Challenges}

- Infrastructure, capacity and specialised tools required to maintain REFELA secretariats at least at regional level

- Need to integrate monitoring and evaluation with learning

- Need to focus more on matching mentors with mentees according to values, personality, and expertise

- Barriers to include gender equality messaging in political campaigns

- Barriers exist in terms of socio-cultural norms from a gender perspective

- Limited access to technology and networks in grassroots spaces

\section{O Examples}

- REFELA-UCLG training on Gender sensitive budgeting, 'Guaranteeing women's rights at the local level', and Digital literacy to provide knowledge and enable administration through modern technology

- Mentoring of younger, upcoming politicians by former REFELA presidents in Mauritania, Cameroon, Gabon

- Canada's feminist approach to International Assistance focuses on closing the gender gap and increase participation of vulnerable and marginalised groups in key decision making processes

*For additional information and main contact for this case study please refer to Annex 2 
There continues to be the need to create separate spaces and structures to enable the sharing of technical expertise in ways that strengthen the capacities of LRGs in the global north and south. Stakeholders pointed to this as an important distinction in development cooperation methods and objectives, involving both on the ground local and in peer-to-peer learning activities, as well as across policies, practices, and advocacy of LRGAs. The more complex a multi-tiered cooperation system becomes, the greater is the inherent risk of crowding out opportunities for lesser-resourced and under-capacitated actors. This includes tangible opportunities to shape and to lead local and global initiatives towards inclusive policies, practices, and outcomes. ${ }^{20}$ Several stakeholders pointed out that these have tended to be far removed from onground reality when it comes to implementing actions to achieve global compacts on sustainability. This meant that requests for assistance on achieving the SDGs, for example, were more common than local adaptive or mitigative climate action across decentralised cooperation networks. Ironically, this prevented decentralised cooperation from being truly bottom-up. Sogen Moodley suggested that capacity strengthening can be structured to enable 'at least one official in every city or town to think about knowledge management, think about organising to share, and to store knowledge in a local municipality... this would complement a great structure like the CIB framework for cooperation and decentralisation, by providing support for ordinary practitioners'. ${ }^{21}$ This highlights a specific resource and capacity gap amongst very many municipalities that at the moment do not have specific policies in place to action climate initiatives nor are there specific policies to enable learning from one city to another. It also highlights the challenge of convincing national governments in the global South to raise funds or dedicate resources for decentralised cooperation whilst distributing these across the wide range of local government authorities. ${ }^{22}$

\footnotetext{
${ }^{20}$ Interviews with Bernadia Tjandradewi and UCLG ASPAC team, May 28, 2021

21 Interview held on March, 302021

22 Interview with Diana Mitlin, April 6, 2021
} 


\section{Advocacy for learning; learning as advocacy*}

$\begin{array}{lll}\text { Region, focus country } & \text { Levels of governance } & \text { Funded by } \\ \text { Europe, UCLG Learning members } & \text { Municipal, National, Regional } & \text { UCLG Learning }\end{array}$

Description Module 4 on Localising the SDGs, developed with Platforma, is dedicated to SDGs-linked Decentralized Cooperation, and proposes a new kind of cooperation policy and project formatting for cities, local and regional governments, their associations and linked institutions, considering the SDGs principles. UCLG's Live Learning Experience cycle allows officers and staff in cities to connect and engage in the preparation of processes. Leaders may find peers that share visions, technicians can understand trends, get in touch with networks, and distinguish between partners, opportunities and knowledge markets. Both online and on-ground advocacy help build empathy with a place, its people and problems is inspiring for solidarity as well as for the application of practices and lessons learnt.

\section{¿ Best practice}

- Learning by doing

- Investment in technical capacity

- Fostering relationships across North-South: South-South and local geographies
- Specific learning Modules to localize the SDGs

- Transform 'projects' into 'benchmarks' in peer to peer learning

\section{$\triangle$ Challenges}

- LG's expectation to find donors through international work and engagement in UCLG is sometimes not realistic
- Project design, monitoring and evaluation is considered too technical

\section{O Examples}

- Increased global connectivity through online resources provides an opportunity for more open relations and increased cooperation. City performance can be (voluntarily) measured through VLRS

- Practice platforms such as Guangzhou award, OIDP, and PLATFORMA allow progress towards learning between cities and territories and, more transparent reporting

"Advocacy is not an isolated task, nor a strictly bilateral between receiver and donor. The advocacy for more and better cooperation requires knowledge of the political context, as well as examples and practice provided by other local actors (and international peers) " Sara Hoeflich, UCLG Learning Director 


\section{The Town Hall}

UCLG's Town Hall process, ${ }^{23}$ established through their World Congress in 2019, has been an important advancement in creating bottom-up processes and collaboration between civil society organisations and LRGs. It has five content tracks including accessibility, gender equality, and sustainable development. The stated objective is to materialise these tracks through clear partnerships between civil society (which are key organisation) and local governments. The priorities tracks have been "[The Town Hall] process is quite powerful and strong. Members must work with civil society partners to develop a policy paper. Policy recommendations then guide the work plan and mandate/guideline and strategy of policy for the whole network. It is not just about working with the organisation, but it therefore sets out the workplan for the rest of the network. Examples of this have been joint efforts on accessibility and inclusive cities, gender equality, right to the city, and of course sustainable development" - Jean-Baptiste Buffet, (Interviewed on March 26, 2021) identified jointly by local and regional governments and civil society partners. To advance the spirit of bottom-up collaboration, stakeholders highlighted that LRGAs should create opportunities for bureaucratic mobility, enabling substantive placement opportunities for elected representatives and their staff in LRGs to spend time in civil society organisations or other non-governmental spaces.

${ }^{23}$ For further details see https://www.uclg.org/en/policypaper/outcomes 


\section{Section Three: Responding to global challenges through decentralised cooperation}

\section{How do UCLG network members contextualise development cooperation in relation to contemporary global challenges?}

For this study we issued a questionnaire-based survey to all members of the CIB Working Group. We received survey responses from 29 cities spread across 24 countries and six regions. The responses were from 13 local governments, 11 local government associations, one regional government association, three nongovernmental organisations, and one international non-governmental organisation (INGO). 34 per cent of respondents were based in the global south and 31 per cent in the global north. While 21 per cent were located across the north and south.

Figure 5: Locations of survey responses

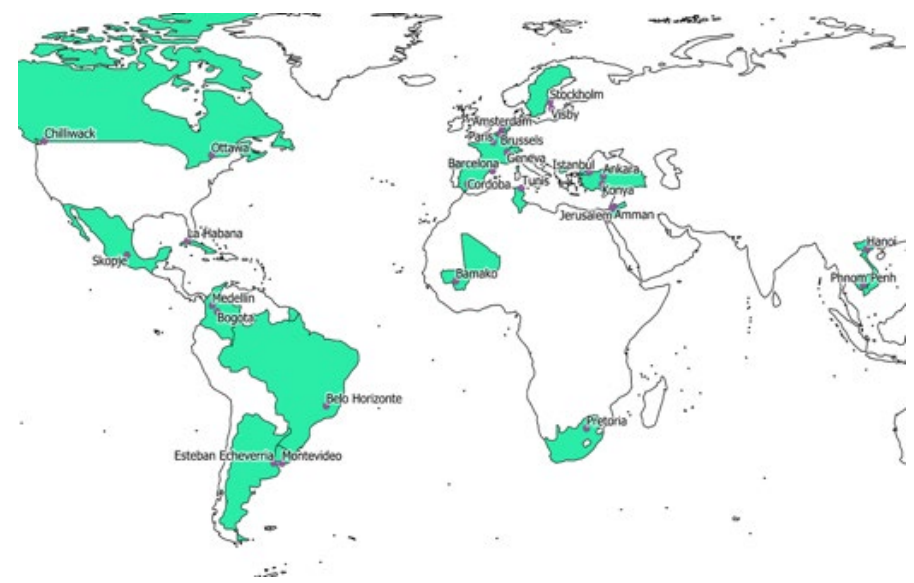

Source: Author's own. The following organisations were also consulted: UCLG Policy; UCLG Local Finance; UCLG Research; Global Partnership for Effective Development Cooperation; United Nations Development Programme; CEMR-PLATFORMA; Durban University of Technology; Swiss Agency for Development and Cooperation; UCLG ASPAC; University of Bristol; Institute of Development Studies; Indian Institute for Human Settlements; University of Manchester; Federation of Canadian Municipalities; Region of Catalonia ORUFOGAR, Capacity and Institution Building working group; VNG International; German Association of Cities; FLACMA; CLGF; UCLG Regional Sections; UCLG Learning Team and CIB working group Reference Group.

Survey respondents were asked what type of cooperation partnerships best describe the ones their organisation is involved in. In the survey responses, we took note of 75 instances of cooperation which respondents described as with partners in the global south, 61 instances which respondents described as with partners in the global north, 46 instances which respondents described as involving national or regional partners, 
and 39 instances of cooperation which respondents described as being within the respondents' city or local region.

As expected, these cooperation activities were spread across a range of SDGs. While most were primarily focused on SDG11 (cities, human settlements), significant proportions of cooperation activity are focused on SDGs 5 (Gender), 13 (Climate), 16 (Peace) and 17 (Partnerships).

When asked what type of evidence respondents use to guide their actions, the most common response (62 instances) was political evidence including government agendas, political assessments, and opportunities. Published research, both peerreviewed (41 instances) and grey literature (55 instances) is also a significant driver of actions.

Figure 6: Location of responding organisation

Where is your organisation based?

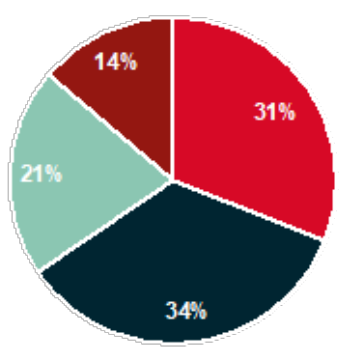

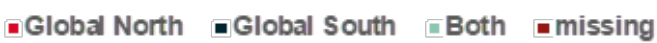

Source: Authors' Own

Figure 7: Level of Cooperation Partnerships

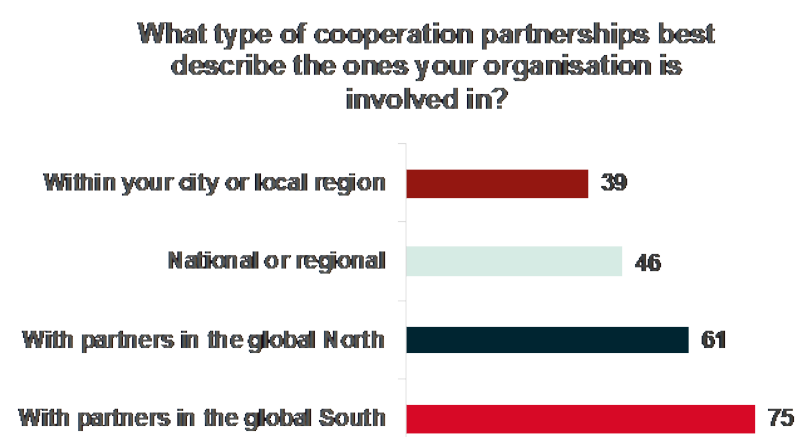

Source: Authors' Own 
Of all these responses, in total 77 instances were described as directed towards capacity strengthening, 31 as financial transfers, 12 as partnerships, 12 as policy change and 4 as directed towards Local Economic Development LED:

Figure 8: Type of Cooperation Partnerships

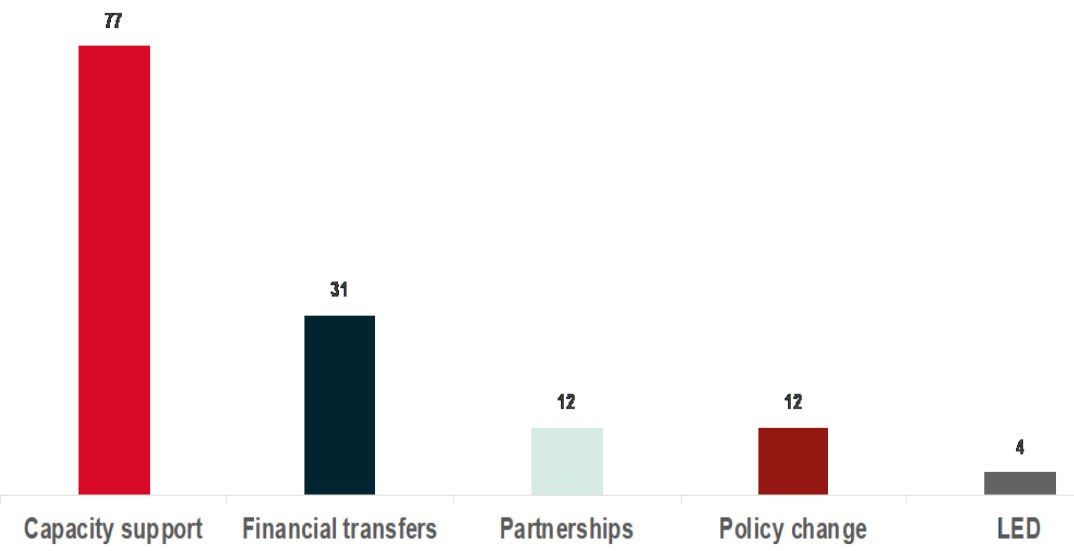

Source: Authors' Own

Figure 9: Types of evidence used in setting organisational priorities

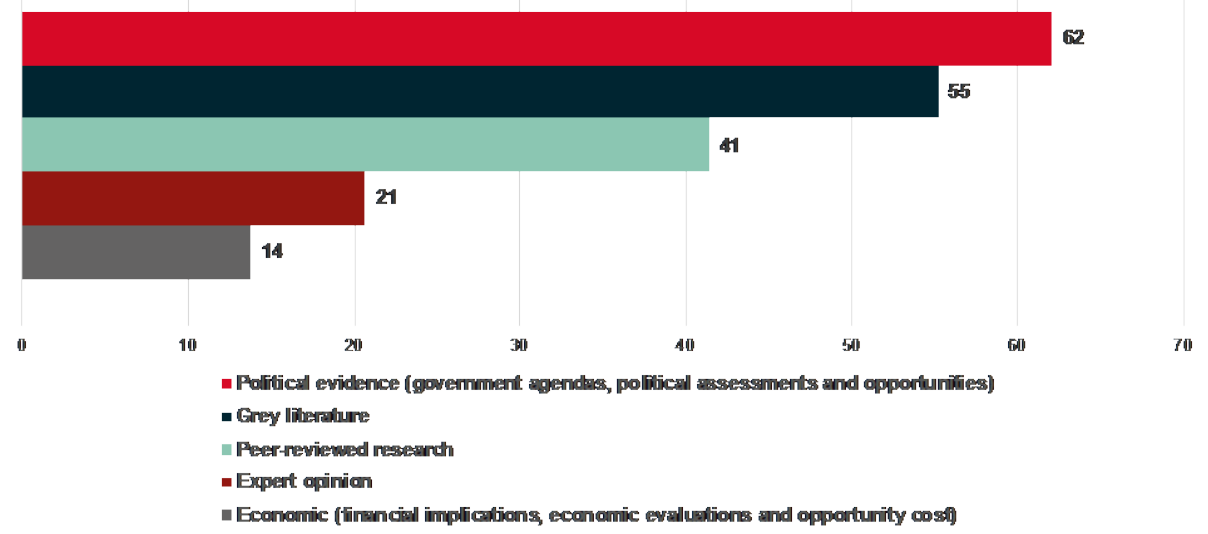

Source: Authors' Own

Given this survey feeds into a policy statement and is intended to drive forward key priorities and actions over the coming decade, it is important to take stock of how network members identify vulnerable or at-risk groups. The responses covered a range of sources, with local planning frameworks being the most common (35 per cent), other significant responses included identification frameworks based on global compacts (ten per cent), and spatial parameters (ten per cent). Official and institutional data is also being used. 
The survey responses also showed a snapshot of the complex and multi-level partnerships across the network. We took note of 57 instances of partnerships reported in the survey responses. These were driven by various levels of authority (respondents) and spread across various levels of partnerships:

Figure 10: Primary means of identifying at-risk or vulnerable groups

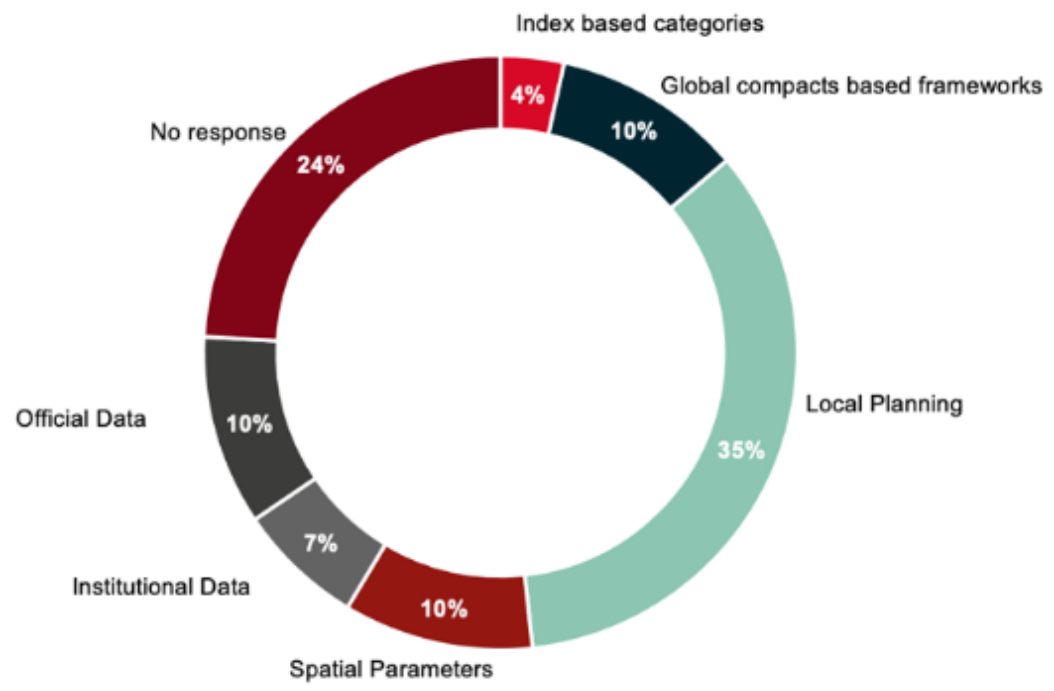

Source: Authors' Own

In the sections below, we describe how the CIB member responses interpreted the four contemporary challenges set forth in this study:

\section{Ecological transformations and climate risks}

Sustainable cities are more likely to use natural resources efficiently, reduce externalities generated by the urban environments. Members reported that strengthening local actors is important to face ecological transformation, and underscored examples of city-city links with specific thematic priorities such as European Green Deal, or adapting/transforming/supporting municipal waste management, or water management can reduce the use of resources. Engaging the circular economy was underscored as an area of significance, and a particularly viable way for LRGs and LRGAs to contribute concretely to climate change adaptation efforts. Networks report prioritising climate action, even if climate change mitigation or adaptation is not a listed priority of their main donor. Some members have organised climate action groups to bring together municipalities and local authorities. For example, climate action will be the main theme of the annual meetings of United Cities France in 2021; while for the Barcelona City Council, these form a key priority area including funding projects as a donor as well as implementing projects. 
Themes and activities drawing the interest of survey respondents from the Latin America region included: prioritising 'eco-system urbanism', electrification of transportation systems, adaption of territorial planning as a tool to reduce emissions, development of strategies to reduce solid waste disposed of in landfill, clean energy, 'climate-smart' buildings in public entities, restoration of trees and preparing a climate strategy for particular groups like climate migrants, adopting health measures that address climate crisis. Respondents also reported relying on local instruments such as the Climate Vulnerability Analysis, Greenhouse gas Emissions Reduction Plan, the New City Master Plans (based on the New Urban Agenda) ${ }^{24}$ as a guide to international projects. The role of different departments such as the Administrative Department of risk management and disaster prevention, planning, environment was highlighted in tackling ecological transformation Some Mayors, such as the Mayor of Bogota, reported integrating environmental transformation as part of their mission or mandate. For instance, the Bogota Development Plan includes a specific target on reducing greenhouse gas emissions. Members reported the importance of recognising action plans particularly in cities or towns where this type of mission-oriented activities are relatively new. Similarly, in Mexico City members reported actions via a consortium which promotes Urban Ecologic Restoration.

Other members, for example the Association of Municipalities of Mali, reported a lack of capacity to deploy actions to support their municipalities, and in particular, to generate finance to address environmental issues, get access to green funds and adaptation financing, as well as to influence national environmental policy despite the existence of international frameworks, and environmental commissions. Incorporating ecological transformation in wider city planning, and attracting international donors thus remain unfulfilled priorities (as was reported in Tunis). Using legal frameworks (such as the law of Environmental Protection, changes in law of Urban Planning) as a tool to advocate for environmentally friendly governance, manufacturing, trading with local governments was also suggested.

\section{Covid-19 and post-pandemic recovery}

Rising authoritarianism in many parts of the world has made development cooperation a challenging task. It became even more acute during Covid-19 crisis when many national governments were seen to deploy measures in autocratic ways. While acknowledging this shift in democratic governance, many members report that it is possible to work together with local authorities. Covid-19 has also resulted in the shrinking of funding avenues for local government development cooperation. Despite limited resources and lack of executive authority, members articulate that service provisioning should not be compromised. In fact, the SDGs provide a guiding framework for post covid recovery measures. The pandemic has also increased investments in Information Technology (IT) infrastructures that have in some ways

${ }^{24}$ See the New Urban Agenda here: https://habitat3.org/the-new-urban-agenda/ 
reduced the digital gap. Members also find that documenting good international practices to guide decision makers can mitigate the effects of the pandemic. It can also prepare for reopening activities of cities. A key recommendation by members was to come up with a comprehensive strategic plan for crisis management that maps the disasters with implications on urban indicators including health, security, economic and social development.

Following sub-sections summarise responses relating to specific aspects about development cooperation such as organisational work and roles, understanding of membership about role of local and their association during and post pandemic, expectation of UCLG's role and other global networks and actors, and finally aspects around monitoring, evaluation, learning and implementation of development cooperation.

\section{How has the work of LRGs and LRGAs been affected by the Covid-19 crisis?}

Organisations are adapting to new ways of working, with some changing roles and responsibilities whilst keeping their focus to meeting the needs of vulnerable populations. International organisations such as VNG have sought to review its organisational structure to increase local ownership and responsibility in times when travel bans are placed. Network of Associations of Local Authorities of South-East Europe (NALAS) adopted a new weekly service to update organisations with changed regulations due to Covid-19 responses and introduced measures such as launch of surveys to assess impact of Covid-19 on local finances for local governments. The municipalities in Brazil shifted their roles as care givers during the pandemic.

Colombia's District Care System was the first in Latin American region to redistribute care work by training care givers and offering care services. The Mayor of Bogota initiated the District Care System which offers care services at the institutional level to redistribute care work. In Cambodia, local government associations worked closely with their members to promote LED.

Perspectives on the role of local and regional governments during the Covid-19 crisis and its aftermath: Given their proximity to citizens, local governments are 'agile' actors. They help identify innovative, contextual solutions at the local level. With access to more data at the local level, local governments are understood as 'bearers of knowledge' of the city's needs, its technical and structural capabilities. In decentralised countries, local governments are responsible for 'social cohesion' by providing service delivery to the population. Covid-19 has underscored the role of LGs as key actors in 'everyday' life in not just provision of basic services but also in ensuring employment opportunities for young people and investing in 'green future'. Examples from Vietnam indicate that local governments were responsible for provision of personal protective equipment (PPE) and food to populations in quarantined areas, controlling migratory flows, provision of adequate vaccines in communities. In post Covid-19 recovery, local governments have been viewed not just as implementers of national plans and policies but also as frontline actors in planning, decision making 
and developing strategies. But this also means that their role is critical in providing leadership and resources to support local businesses. Members recommend that there is a need to combine efforts at both official and community level for delivery of services. They suggest that each institution should develop a cadre to deal with disasters.

But local governments also face intense challenges such as deficits in public finances. Municipalities such as in Tunis, report reduced municipal revenues due to collection of taxes and recession. Many members call for the need to support local governments through polices and increased finances at the local level. Local governments should be seen as catalysts in central government planning and decision making. An example from Turkey illustrates how different tiers of governments have come together. The Union of municipalities of Turkey has started nationwide consultations with the municipalities to develop the Union's policy to be adapted post Covid-19. The municipality is negotiating with central government institutions for raising municipal finances and for delaying or cancellation in the paying off their liabilities.

What is the role of LRGs and LRGAs in the aftermath of the Covid-19 crisis? As articulated in the above sections, local governments have played a multi-dimensional role during the Covid-19 crisis. Members suggest that this transformative role should be recognised at international levels. There is also significant potential in recognising local and regional government associations' roles in localising disaster risk reduction operations. Covid-19 has strengthened coordination between different tiers of government; thus, local governments are key actors in liaising with different tiers of government for effective policies and legislation. Local governments can play an active role to link local communities with the 'outside' world by motivating local communities to bring innovative fresh ideas. In fact, they should also strengthen their existing roles, for example, their function in protecting public health. In terms of assisting local economies, local governments should be proactive in allocating resources and finances to support local economic development. Alliances across cities could also be informative for local governments in sharing methodologies to 'transform cities'.

Monitoring has also been affected which has led to reviews and risk assessments of existing programmes in partner countries, strengthening of local partnerships, and renewal of methodologies to monitor new programmes. With increased reliance on digital platforms, collecting data in real time has become a key constraint. On the other hand, this has meant that more work is being undertaken by local partners and experts. However, members reporting relying extensively on local experts in partner countries. Members also find that online reporting comes with its own challenges making it difficult to measure progress. They report that some partners don't have resources and tools to undertake this exercise virtually. There is also a view that the shift to virtual communication has made projects economically efficient. It has also led to a wider geographical spread of partners. 
Digital adaptation in project activities has meant more innovative ways of learning. Many online platforms now feature ways of sharing good practices, real time updates, and new learning tools. Organisations have designed training modules for their staff to lead successful online meetings and conferences. While remote working has led to wider participation, diversified audiences, and inclusive voices, work hours have increased. In fact, there is a sense of heightened work pressures amongst the membership. Digital divides are also experienced in remote areas with fractured internet connections. Digitalisation has also impacted bureaucratic tasks with delays in biddings, contracting, and import of goods (as mentioned by a respondent in Cuba). In Brazil, deduced face-face interactions of the Mayor affected communities with no access to digital infrastructures. Members underscored that language barriers can make virtual workshops and training sessions difficult. While there has been more participation and connectivity between cities through digital tools, exchange of ideas has been challenging in comparison to face-face interactions. 


\section{Pivoting to online learning during the pandemic*}

\begin{tabular}{lll} 
Region, focus country & Levels of governance & Funded by \\
\hline $\begin{array}{l}\text { Asia Pacific, } \\
\text { Indonesia }\end{array}$ & Municipal, National & EU'S LOCALISE SDGs programme \\
\hline
\end{tabular}

Description UCLG ASPAC organised 'coaching clinics' to create synergies between national and local governments, with LRGs provided an online space to consult and ask questions to experts through these clinics. The main topics of discussion included inter alia: i) alternative financing for environment, ii) food security, iii) economic digitalisation, iv) data integration (for social safety net), v) tourism and vi) online health service (telemedicine).

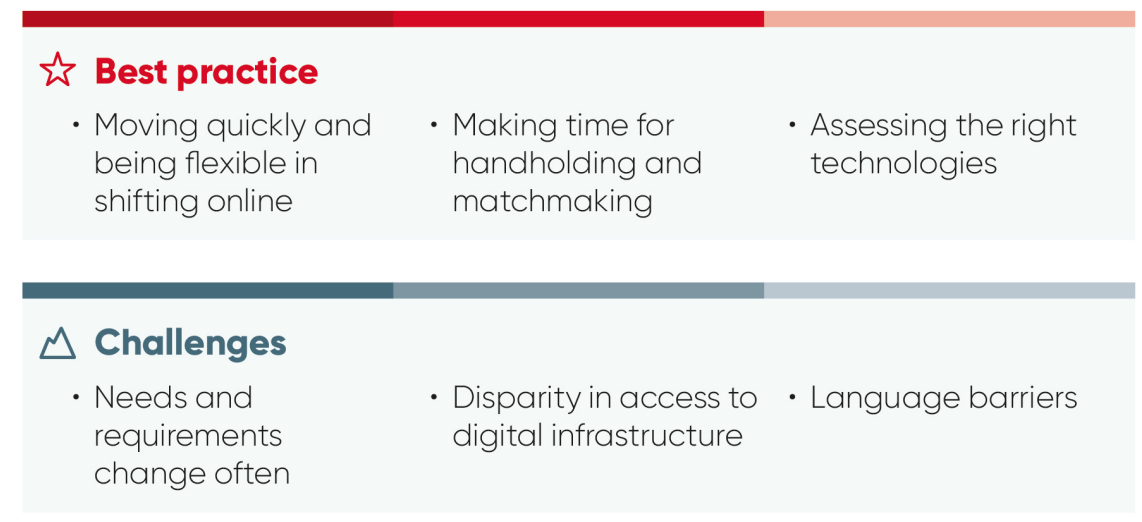

\section{O Examples}

- Two LGs from Maluku Province and Gorontalo City have considered and successfully obtained loans from the third party (PT SMI) after attending a coaching clinic session

- LRGs have initiated tax payment reform by the increasing use of mobile devices, and creating a platform for online tax payment which supports the government's Covid-19 response

- Participating LGs developed a virtual tour program

- Bengkulu City successfully built partnership with BAZNAS (Indonesia's National Zakat Agency) in support of SDGs attainment in Bengkulu

"We see the importance of having consultation clinics as more like a guidance coming from national governments to the local governments to deal with the local situations. So it was responding to the clear and immediate need of the pandemic situation." Interviewee from UCLG-ASPAC 
While there has been an increase in participation through online platforms, networking opportunities have significantly reduced. Rolling out programmes and activities has been particularly difficult with limited face-face interactions. Members find that individual learning process is compromised because of difficulty in exchange of ideas through online platforms. There is also a view that face-face interactions are more efficient as some respondents think that learning is contingent on the nature of activity. Some activities require face-face interaction for better understanding among participants. Networks like the Federación Latinoamericana de Ciudades, Municipios y Asociaciones de Gobiernos Locales (FLACMA) also organised virtual spaces for exchange of dialogue and sharing ideas of municipal management, and challenges that are faced during the pandemic.

When travel restrictions were imposed, the quality and delivery of programmes in partner countries is reported to have been severely affected. Projects plans have been delayed, with some undergoing budgetary changes. Projects are redirected in nonpriority areas. Relationships with different actors and formation of alliances has also halted because of travel bans. Members report prioritising discussions around improving access to aid and how the demand for reallocation of funds could be requested. Development cooperation has also been impacted severely in leastresourced contexts with limited access to technology particularly with respect to designing project activities. Development cooperation has also been severely affected in the space of human rights advocacy. In Geneva, where civil society activists are hosted from across the world, travel restrictions have hampered this human rights work.

What specific role could UCLG, its members and its network play? UCLG's role is important in creating spaces for sharing of experiences across cities. These spaces should not be limited to politicians but could also include networks of technical experts in local authorities. More platforms for opportunities of joint projects with international donors should be introduced. In fragile contexts such as Mali, UCLG should support more pandemic related initiatives. In developing countries with limited financial or human resources, UCLG could ensure capacity building at the local level. For creating recovery policies premised on inclusiveness and transformation, SDGs could be used as a framework.

In times of austerity, advocacy messages should be steered towards increasing budgets for development cooperation, together with putting forward interests and role of local and regional governments in international cooperation. UCLG should develop an international framework to facilitate and promote decentralised cooperation and actively lobby with multilateral organisations like the UN, and EU for resources and mechanisms to promote decentralised cooperation. To mitigate the effects of Covid19 , it should engage with international donors on direct provision of aid to local 
governments. As a global network of various actors, UCLG should encourage dialogues with stakeholders on development cooperation now and post-Covid-19.

In thematic terms, UCLG could create thematic clusters to facilitate engagement for development cooperation at the global level. Tools that could potentially be used to facilitate local authorities to improve or initiate international cooperation include (i) setting up working groups such as the $\mathrm{CIB}$, (ii) initiating webinars and meetings, (iii) circulating of key documents and (iv) setting up a hub or advisory centre for municipalities encourage participation and exchange of information on post-Covid-19 contributions.

\section{Gendered inequalities, and unequal access to basic services}

Majority of respondents have acknowledged that gendered inequalities come in various forms at both government and community levels. 'Mainstreaming of gender' has been largely understood through (i) equal representation and participation of women in politics and local government (affairs), (ii) developing leadership among women who hold public office, (iii) feminising male-dominated sectors (iv) reducing violence against women whether in government offices (eg., municipalities), or at the community level, (v) redistribution of unpaid reproductive work particularly during the Covid-19 crisis, (vi) working with men to reduce gender-based discrimination, (vii) LGBTQ+ (lesbian, gay, bisexual, transgender, queer, plus). In order to achieve these, a number of strategies/pathways have been reported by UCLG members as tools, projects, initiatives, and programmes.

Members expressed that equal representation within municipalities is being undertaken through specific gender programmes that promote women in local governments. Organising of events (for Local Elected Congress Women), study tours (Stockholm example), and awareness workshops also support and strengthen women's position in political affairs. Gender-based budgeting and mainstreaming gender perspective in local policies such as security, public space and other social services are key gender-based strategies for some members. The inclusion of women and young people in local government affairs has also happened through strategies like scaling up of initiatives that focus on redistribution of care work (Bogota's District Care System). Furthermore, formation of gender groups in particular focal points, women's commission at the municipal level (South African Local Government Association (SALGA)), and initiatives like Women Support Committee (Municipality of Aizaria) can potentially reach women and raise their issues at decision making tables. The Mayor of Bogota has established affirmative measures to increase hiring in the capital district. Women's participation in sectors like infrastructure and transport that are dominated by men is being encouraged in Bogota. Other initiatives include setting up monitoring activities for implementation of SDG 5 . 


\section{Capacity building of associations *}

Region, focus country

West Africa, Belgium
Levels of governance

Municipal (local authorities), National (national associations)

\section{Funded by}

The Federal Government of Belgium

Description The Association of Flemish Cities and Towns (VVSG) strengthens capacity of its sister association, the Association Nationale des Communes du Bénin (ANCB) in Benin to integrate gender equality at the local level. Twelve municipalities in Benin will first experiment how gender equality is implemented, and gradually this pilot will be scaled up to all 77 municipalities in Benin. These municipalities include Agbangnizoun, Bohicon, Dogbo, Houeyogbé, Lalo, Ouinhi, Toviklin, Za-kpota, Materi, Pèrèrè, Péhunco and Toucountouna. These pilot municipalities are supported by ANCB individually, but all of them come together every year to learn from each other through exchanging their experiences.

\section{is Best practice}

- Strengthening of local governance structures within the municipalities of Benin
- Building partnerships with universities to develop strategies for gender equality
- Organising crosslearning visits and across geographies

\section{$\triangle$ Challenges}

- Contending with long standing social and cultural barriers

- Gaps in local expertise on gender equality

\section{Oxamples}

- VVG and ANCB have worked with University of Leuven (Belgium) and University of Parakou (Benin) to develop tools and templates that identify specific gender equality projects and activities in local policies

- Female councilors part of Network of Locally Elected Women jointly identified topics that could be elevated for discussion at the national level

- VVS organised study visits for Benin to learn from Belgian and Flemish Associations of how these municipalities work on gender. WVSG has also organised trainings for Flemish Associations to integrate gender equality 
Respondents acknowledged that sexual violence as a challenge is dealt with internally (that is within the municipality through local public policies) as well as externally (with the public). [Council of Barcelona]. Drafting of tools and methodologies, training municipal staff, development of local protocols form key areas of action (Morocco's example of EQUALMED of how the programme centres gender in local public policies). In Bogota, initiatives like Psycho-Emotional Line of Attention for Men called The Calm Line and a School of Learning for Men are being set up with the objective to work with men through helplines and learning courses to prevent gender-based violence, promote non-violent, equitable and caring masculinities, and focus on a pedagogical agenda against multiple forms of discrimination. In Brazil, the Council of Belo Horizonte undertakes projects for mainstreaming not only gender but other forms of vulnerabilities (colour, race, gender identity, LGBTQ+) through trainings in entrepreneurship and digital transformation. It was noted that for some members, inclusion of people with disability in programming is a priority.

\section{Accessing Green Finance}

The predominant view of the respondents was that the concept of 'Green Finance' is new to their budgeting and fund-raising systems. There is also a view that the focus towards green financing has become much more prominent with the intensification of climate change, and projects are required to be designed based on green financing for development. Notwithstanding, there are several achievements worthy of mention:

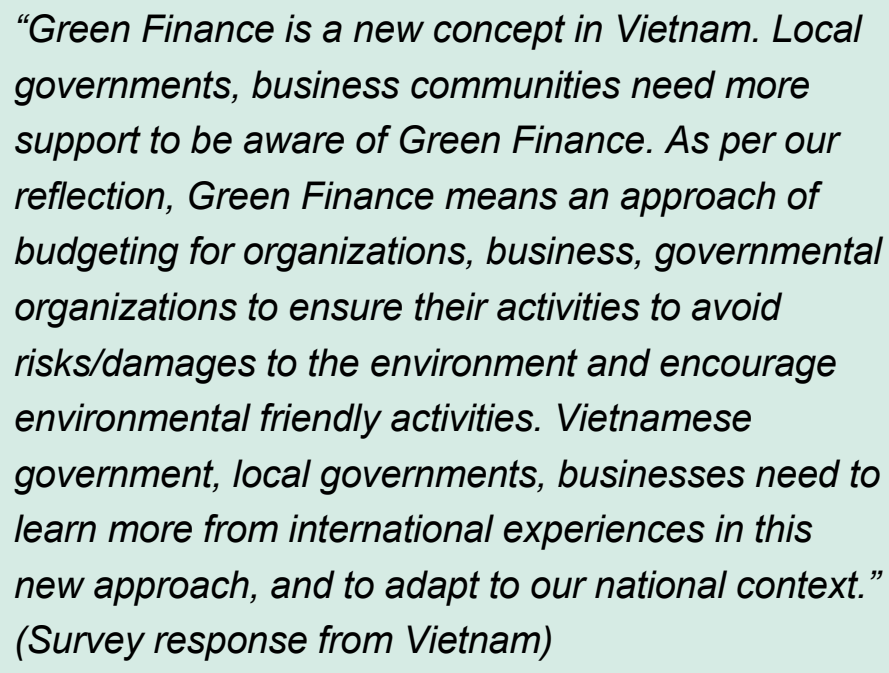

Some networks and working groups such as the Network of Cities and Peoples Towards Sustainability have published accessible guides (Guide on Circular and Green Economy in the Local World: How to Move to Action and Tools for Local Entities ${ }^{25}$ ) which provide a framework towards achieving circular and green economy these guides reflect local knowledge and practices of the circular economy. Respondents understood that the nature of impacts regulations around green finance are having and will likely have. For example, the EU Green Deal will have implications for the Dutch municipalities, in their local operations, as well as the nature and substance of their international partnerships. Similarly, in Latin America, opportunities were identified for groups such as the NALAS Fiscal Decentralisation Task Force, which publishes reports on local traditional financing

25 Survey response from the Provincial Council of Barcelona 
instruments, and analyses the local government finance system and its instruments in the East European region, who are well placed to refocus their reports on adaptation finance. Cities such as Bogota are already exploring funding structures based on green bonds to prioritise issues such as sustainable mobility through the electrification of transport systems, and funds are being generated at the district level for energy and technological transition of cargo. Responses from Argentina expressed that municipalities could incorporate sustainability criteria into their subsidies, while Agencia de Cooperación e Inversión de Medellín (ACI) is an example of an LRGA that understands the close relationship between local government financing, sustainability and the dynamics of cooperation and therefore encourages the city to apply as many innovative financing mechanisms as possible. In Cuba, energy efficiency, solid waste recycling, green insertion in the urban fabric are key projects that form part of the development plans. 


\section{Decentralised cooperation through Local Economic Development*}

Description The Partnerships for Municipal Innovation (PMI), involving the Federation of Canadian Municipalities (FCM) and the Commonwealth Local Government Forum (CLGF), supports local governments, their partners and communities pursue local economic development. The LIF is principled on good governance, civic engagement, sound planning, transparency and accountability. It strengthens project management capacities of the local governments to institutionalise LED within national guidelines or frameworks.

\section{is Best practice}

- Seed funding to motivate local initiatives

- Identifying business opportunities at the city level by working closely with LED communities

- Use of intellectual property rights to implement projects successfully

- Developing monitoring tools focused on environmental sustainability with consultations from LIF grant holders and beneficiaries

- Understanding local value chain concepts with local governments and entrepreneurs

\section{$\triangle$ Challenges}

- Low human resources and LED expertise in particularly in smaller regions and towns

\author{
- Mobilising local \\ resources for \\ matching fund \\ conditioned by the \\ LIF application
}

\section{- Administrative bottlenecks at the city level}

\section{O Examples}

- In Cao Lanh, Vietnam, the LIF is used for entrepreneurial training for informal workers, strengthening women's business support networks

- The Ministry of Local Government, the Local Government Association of Zambia (LGAZ), and the Chalimbana Local Government Training Institute (CLTGI) have developed LED guidelines, implemented the Decentralization Policy and the National Development Plan, and the Chipata Municipal Council established an interdepartmental team of council 
Other noteworthy examples include the Amman Resilience Strategy ${ }^{26}$ which is a partnership between the city and a number of international and local institutions aims to build resilience \& sustainability in the city by focusing on (i) transport and mobility, (ii) smart cities applications and transformation, (iii) the environment and facing the effects of climate change, (iv) the societal and economic pillar, (v) infrastructure, (vi) urban planning, (vii) health and social welfare, and (viii) renewable energy. In Turkey, Green Sukuk (or Shari'ah compliant investments in renewable and other environmental assets ${ }^{27}$ ) are being encouraged in developing sustainable financing models with national and international donor organisation, while in Tunis, Tunisia, ongoing work with donors is prioritising interventions, and access funding for green cities.

\section{Workshop on Local Government and Development Cooperation}

"We achieved a lot in the past year to convince the donors about investing in local govts and accepting the role they can play in the development of countries. This gives us a new responsibility because we shape development together with local governments and with nongovernmental organisations which raises a lot of expectations about the quality, the professionalism of our work and the fact that we are on a new path towards building a new social contract in the world between citizens and public administration. Despite all what we have achieved, it is still a task of convincing many national governments that local and regional actors that can play a role in developing the local government sector of their own country. They should receive finances to do that but also to enable the local government sector to be a partner in this field. It is important to keep in mind that municipal international cooperation changes all the time. It is quite dynamic." Peter Knip (Director VNG International)
A workshop on Local

Government and Development Cooperation structured around the questionnaire responses was held on $8^{\text {th }}$ June 2021 which generated a multifaceted definition of cooperation, as well as an engaging discussion on how cooperation works at multiple frontiers. The workshop was attended by 50 participants who represented UCLG membership from across different regions of the network. In her opening remarks, Emilia Saiz

emphasised on the significance of development cooperation and stressed the importance of framing the discussion within the context of renewed pact for the future and as a new social contract centred around people, the planet and government.

\footnotetext{
${ }^{26}$ Survey response from Amman's Head of Foreign Relations Division

${ }^{27}$ For further details, see https://www.climatebonds.net/projects/facilitation/green-sukuk
} 
In the breakout activity ${ }^{28}$, participants engaged in discussions to deepen understanding of how cooperation works through different frontiers. The findings focus on three specific aspects of cooperation:

\section{Operations and engagement with cooperation institutions and infrastructures} (analogue and digital): Responding to the leading question of 'What is the current level of readiness of cooperation institutions and infrastructures (analogue and digital) to meet contemporary challenges?', workshop participants were asked to reflect on or provide examples of how they can ensure their constituents share their enthusiasm for cooperation, and what existing and potential capacity strengthening tools can enhance mobilisation.

Cooperation activities rely heavily on institutions which must be able to endure political changes and bureaucratisation. Strong institutions can in fact help develop stronger alliances across cooperation actors that meet local needs and global agreements in a sustainable manner. The experience of Medellín (Colombia) is useful in understanding how institutional building has led to continued cooperation work for about two decades. Governments as cooperation actors should also have the flexibility to direct resources towards disasters and risks. The Belgian federal government, for example, has had the flexibility to redirect subsidies for Covid-19 response. While digital interfaces may be good avenues for communication, they may not generate quality interactions. Despite the increasing reliance on online fora, there remains a need to build relationships centered on values of trust and information through physical contact. Interestingly, the pandemic has shaped cooperation by accelerating investments in technological capacity, but it has also provided the infrastructure to do development cooperation. There exists substantive potential to align international cooperation agenda to SDGs and create common indicators of impact. This could take the form of learning and capacity building for regional SDGs monitoring and reporting.

Constituents can be engaged and made enthusiastic about cooperation through several ways such as: (i) creating spaces for leadership by examples with mayors convincing mayors; (ii) creating more engaging ways of communication such as setting up committees on international cooperation, or standing committees in the governance structure of nations; (iii) adding more delegations that come with politicians, technocrats, and other actors; (iv) localising cooperation topics by asking questions rooted in one own's municipality and partner municipality; (v) working with public administration such as politicians and technicians to train them in generating a cohesive city strategy cooperation; (vi) nurturing learning about cooperation by telling constituents that it involves establishing their priorities and allies; (vii) building communication strategies that show the impact of cooperation in everyday life.

${ }^{28}$ Refer to Annex 1.2 
Partnerships and engagement: Responding to the leading questions 'How intensive is the current level of engagement between cooperation actors with civil society, universities, businesses, and entrepreneurs at the local level?', workshop participants were asked to reflect on what tools, actions or innovations are required to activate or strengthen partnerships and asked to provide examples or lessons of 'learning to advocate for change together'.

In countries where there already exist strong academic infrastructure or culture of engagement, there is a strong desire to engage in cooperation. But in contexts where academia is not well funded, engaging in cooperation may be difficult. While there are instances of partnerships with academia, more work needs to be done to engage with civil society and the private sector. With the evolving landscape of emerging economies, there is also a growing need to develop South-South partnerships. In a post Covid-19 context, these relationships and networks of solidarity look very different, but it is important to continue delivery of services. Entrepreneurs, small and medium businesses take big risks as it hard for them to engage international actors in unknown contexts. This in fact makes an important role for cooperation actors to engage business actors who find themselves operating in unknown and uncertain settings. Amongst a range of cooperation actors, there also is a need to create alliances with shared risks at multiple levels. But this multi-level work may bring some other challenges such as legislative and budgetary limitations. From a thematic perspective, steering discussions towards topics that are already gaining traction in international development such as climate action can be instrumental in establishing long term partnerships between networks and donors.

At the local level tools, actions or innovations are required to activate or strengthen partnerships. These can take different forms. For instance, a legal framework could be essential in facilitating the building of alliances across the public-private spectrum given that each country's legislation is different. It is also necessary to find the balance between facilitating the insertion of the private sector in a scenario that is risky for local actors and their commitment to achieve a more equitable development. Funding for multistakeholder initiatives is also essential to strengthen partnerships at different scales.

Financing: Responding to the leading question 'How flexible is the current financing available for cooperation?', workshop participants reflected on the lessons learned from successful fund-raising strategies and provided examples of innovative fundraising opportunities. 
The predominant opinion was that the current financing landscape lacks flexibility and is prescriptive with donors limiting to areas and timeframes to invest in funds. Members find that local governments have relatively less freedoms to present the needs of their constituencies. One member said, '...funding is often seen as creating power relations. Those who manage funds have limited willingness to dedicate parts of their budget...' Even though, more mainstream mechanisms of financing might be less flexible, there are some innovative strategies such as (i) crowdfunding which brings more funders, more interest, and a range of stakeholders; (ii) adopting a project-based strategy for fundraising itself which then allows finding new partners and not just funding only. Some successful examples include the Global taskforce of crises and disaster recovery that raises funds of small LG in France. Finally, members find that there is potential to create regional funds for cooperation. It will be important if financial agencies include a component of decentralised cooperation given that decentralised cooperation is sustainable and long term through partnerships.

'Decentralised cooperation should be understood as a strategic tool to build leadership at the local level using the principles of inclusive partnership for sustainable development for citizens. Handbooks such as the decentralised cooperation handbook being developed by Platforma and NALAS will serve as a key advocacy tool for decisionmakers at national, local, and regional level. The handbook comprises of a number of good practices in decentralised cooperation, good city-city cooperation after a city enters development cooperation. Peer-peer learning which is the best way of how to transfer in a systematic way.'

(Joachim Roth, NALAS).
"We need a sheer understanding of reciprocity, synchronisation in the global scenario, national and regional level planning. Local governments want to know that there is synchronisation which will then be reflected in the global and national agenda. We know that there is potential but we need to have a strong advocacy on this. We know doing it. We cannot just depend on the spirit of solidarity for having decentralised cooperation. We cannot just depend on the spirit of kindness. We need to find a faster multiplier effect at the sub-national, local and regional level. We have to have a combination of advocacy, capacity development and knowledge sharing." - Bernadia Tjandradewi (Secretary General, UCLG ASPAC) the potential, we know the value, and the benefits 


\section{Section Four: Future directions for decentralised cooperation: what, where, with whom and how}

The meaning and practical nature of decentralised cooperation has evolved significantly over the past decades. A major achievement has been the adoption of key concepts of localisation within all major international cooperation paradigms and global compacts aimed at sustainability. This created space on the proverbial table for local and regional actors amongst national and transnational ones. These key achievements notwithstanding, a shifting international order with the BRICS and emerging economies expressing new relationships and objectives, as well as the heightening and complex nature of contemporary global challenges, necessitate a fresh look at the role of local and regional actors, and the strategic objectives of decentralised cooperation.

Following a systematic review of the literature on decentralised cooperation, a series of key stakeholder interviews with LRG and LRGA representatives, a questionnairebased survey of CIB Working Group members, and a key stakeholder workshop, this study has distilled the following generalisable parameters for decentralised cooperation actors to consider in setting their strategic priorities for the coming years:

- What guiding principles and strategic vision should LRGs and LRGAs adopt to pursue decentralised cooperation? What are the frameworks in which LRGs are working in the context of delegated authority and redistribution? Decentralised cooperation is already a mainstay of any serious pursuit of sustainable development. The urgent and intensifying nature of global challenges, as well as opportunities and innovation inherent at the local and regional level imply an everincreasing responsibility for local and regional actors. As such, networks and associations must be driven by a central objective to empower and enable local and regional actors. At the same time, they must continue to be open and inviting to actors operating at non-local scales. This includes deliberate and complementary strategies to build relationships with UN bodies, as well as national forums.

- Where should decentralised cooperation networks and associations focus their strategic activities? It is pertinent for networks of (or for) cities, as well as those of or for local governments to focus their efforts on cities, city-regions, and subnational regions where urban change is greatest, and therefore significantly impacting local development. This necessarily places the fast-urbanising regions in Asia (China, India) and Africa (a selection of countries with the highest urban 
growth rates includes Burundi, Burkina, Ethiopia, Madagascar, Angola, Nigeria) as a priority. However, this also includes key regions in Latin America, Europe, North America, where city- and city-regions are showing leadership and distinctly shaping sustainable futures. Furthermore, it is pertinent for LRGs and LRGAs to continually understand where national governments are extracting finance from, and how is it re-distributed across the urban network. While current development assistance tends to be rooted in North-South, donor-driven concepts, there is an urgent need to harness discussions about local government financing.

- With whom should decentralised cooperation networks and associations focus their strategic partnerships? Networks like UCLG already have an impressive range of collaborative and multi-scalar partnerships, and these are built on mutual trust and respect for individual mandates. As LRGAs responds to the changing nature of contemporary challenges, they must consider how new strategic partnerships, for example with university and research stakeholders, can help strengthen evidence-based action, and help position LRGAs in relation to key debates (for example on climate, security, inequality etc). The evidence base is also critical in understanding and aligning with changing donor priorities.

- How should decentralised cooperation networks and associations strengthen their operation? In particular, how can LRGAs advance on bridging the gender gap and including more women's voices when the number of elected women remains very low in country contexts? Capacity strengthening (learning) presents a key pathway to meet current and future organisational challenges. Strategic actions to align learning and advocacy efforts will help identify locally relevant themes, and this will reflexively determine how curricula should be defined. 


\section{Bibliography}

Acuto, M. (2013) 'City Leadership in Global Governance', Global Governance 19.3. 481-498 (accessed 19 November 2021)

Acuto, M. and Rayner, S. (2016) 'City Networks: Breaking Gridlocks or Forging (New) Lock-Ins?', International Affairs 92.5: 1147-1166, DOI: 10.1111/14682346.12700 (accessed 19 November 2021)

Agranoff, R. (2014) 'Local Governments in Multilevel Systems: Emergent Public Administration Challenges' The American Review of Public Administration 44(4_suppl): 47S-62S, DOI: 10.1177/0275074013497629 (accessed 22 November 2021)

Amis, P. (2013) 'Local Government: How does it fit into the Post 2015 MDG Agenda?', Commonwealth Journal of Local Governance 13/14: 4-16, DOI: 10.5130/cjlg.v0i13/14.3720 (accessed 22 November 2021)

Araos, M.; Berrang-Ford, L.; Ford, J. D., et al. (2016) 'Climate Change Adaptation Planning in Large Cities: A Systematic Global Assessment', Environmental Science \& Policy 66: 375-382, DOI: 10.1016/j.envsci.2016.06.009 (accessed 22 November 2021)

Bontenbal, M. C. (2009). 'Strengthening Urban Governance in the South through City-to-City Cooperation: Towards an Analytical Framework', Habitat International 33.2: 181-189, DOI: 10.1016/j.habitatint.2008.10.016

Buchner, B., Herve-Mignucci, M., Trabacchi, C., et al. (2014) Global Landscape of Climate Finance 2015, London: Climate Policy Initiative (accessed 22 November 2021)

Colenbrander, S.; Dodman, D. and Mitlin, D. (2018) 'Using Climate Finance to Advance Climate Justice: the Politics and Practice of Channelling Resources to the Local Level', Climate Policy 18.7: 902-915, DOI:

10.1080/14693062.2017.1388212 (accessed 22 November 2021)

Gu, J. and Kitano, N. (2018) 'Emerging Economies and the Changing Dynamics of Development Cooperation', IDS Bulletin 49.3, DOI: 10.19088/1968-2018.143 (accessed 22 November 2021)

Guha, J. and Chakrabarti, B. (2019) 'Achieving the Sustainable Development Goals (SDGs) through Decentralisation and the Role of Local Governments: A Systematic Review', Commonwealth Journal of Local Governance 22: 1-21, DOI: 10.5130/cjlg.v0i22.6855 (accessed 22 November 2021)

Gupte, J. and Mitlin, D. (2021) 'COVID-19: What is not being Addressed', Environment and Urbanization 33.1: 211-228, DOI: 10.1177/0956247820963961 (accessed 22 November 2021) 
Hafteck, P. (2003) 'An Introduction to Decentralized Cooperation: Definitions, Origins and Conceptual Mapping', Public Administration and Development 2.34: 333-345, DOI: 10.1002/pad.286 (accessed 22 November 2021)

Herrera, V. (2019) 'Reconciling Global Aspirations and Local Realities: Challenges Facing the Sustainable Development Goals for Water and Sanitation', World Development 118: 106-117, DOI:

10.1016/j.worlddev.2019.02.009 (acccessed 22 November 2021)

Holmes, R. (2021) Integrating Gender and Inclusion in Social Protection Response to COVID-19: What have we Learnt?, London: SPACE (accessed 22 November 2021)

ICLEI (2021) ICLEl in the Urban Era: Our Vision for a Sustainable Urban World. Bonn: Local Governments for Sustainability (ICLEI) (accessed 22 November 2021)

Janus, H.; Klingebiel, S. and Paulo, S. (2015) 'Beyond Aid: A Conceptual Perspective on the Transformation of Development Cooperation', Journal of International Development 27.2: 155-169, DOI: 10.1002/jid.3045 (accessed 22 November 2021)

Joseph, C. and Maluka, S. O. (2017) 'Do Management and Leadership Practices in the Context of Decentralisation Influence Performance of Community Health Fund? Evidence From Iramba and Iringa Districts in Tanzania', International Journal of Health Policy and Management 6.5: 257-265, DOI:

10.15171/ijhpm.2016.130 (accessed 22 November 2021)

Keohane, R. O. and Victor, D. G. (2016) 'Cooperation and Discord in Global Climate Policy', Nature Climate Change 6.6: 570-575, DOI: 10.1038/nclimate2937 (accessed 22 November 2021)

Krukowska-Siembida, P. (2020) 'Bases of International Cooperation of Local Governments', Lex Localis-Journal of Local Self-Government 18.4: 885-900, DOI: 10.4335/18.3.885-900(2020) (accessed 22 November 2021)

Lambert, H., Gupte, J., Fletcher, H., et al. (2020) 'COVID-19 as a Global Challenge: Towards an Inclusive and Sustainable Future', The Lancet Planetary Health 4.8: e312-e314, DOI: 10.1016/S2542-5196(20)30168-6 (accessed 22 November 2021)

Li, X.; Gu, J.; Leistner, S. and Cabral, L. (2018) 'Perspectives on the Global Partnership for Effective Development Cooperation', IDS Bulletin 49.3, DOI: 10.19088/1968-2018.153 (accessed 22 November 2021)

Maluka, S.; Chitama, D.; Dungumaro, E.; et al. (2018) 'Contracting-Out Primary Health Care Services in Tanzania towards UHC: How Policy Processes and Context Influence Policy Design and Implementation', International Journal for Equity in Health 17.1: 118, DOI: 10.1186/s12939-018-0835-8 (accessed 22 November 2021)

McFarlane, C. (2008) 'Governing the Contaminated City: Infrastructure and Sanitation in Colonial and Post-Colonial Bombay', International Journal of Urban 
and Regional Research 32.2: 415-435, DOI: 10.1111/j.1468-2427.2008.00793.x (accessed 22 November 2021)

McFarlane, C. (forthcoming) 'Repopulating Density: COVID-19 and the Politics of Urban Value', Urban Studies 0.0, DOI: 10.1177/00420980211014810 (accessed 22 November 2021)

Nganje, D.F. (2015) Decentralized Cooperation and the New Development Cooperation Agenda: What Role for the UN?, New York City: UNU-CPR (accessed 22 November 2021)

OECD and European Commission (2020) Cities in the World: A New Perspective on Urbanisation, OECD Urban Series, Paris: OECD (accessed 23 November 2021)

Ojeda Medina, T. (2020) 'El Rol Estratégico de los Gobiernos Locales y Regionales en la Implementación de la Agenda 2030: Experiencias desde la Cooperación Sur-Sur y Triangular', OASIS 31: 9-29, DOI: 10.18601/16577558.n31.03 (accessed 23 November 2021)

Pelling, M.; Chow, W. T. L.; Chu, E.; et al. (2021) 'A Climate Resilience Research Renewal Agenda: Learning Lessons from the COVID-19 Pandemic for Urban Climate Resilience', Climate and Development: 1-8, DOI: 10.1080/17565529.2021.1956411 (accessed 22 November 2021)

Renwick, N. (2018) 'Emerging Economies, Disaster Risk Reduction, and SouthSouth Cooperation: The Case of Mexico', IDS Bulletin 49.3, DOI: 10.19088/19682018.149 (accessed 23 November 2021)

Shimomura, Y. and Ping, W. (2018) 'Chains of Knowledge Creation in the Evolution of New Donors', IDS Bulletin 49.3, DOI: 10.19088/1968-2018.147 (accessed 23 November 2021)

UN-HABITAT (2020a) Breaking Cycles of Risk Accumulation in African Cities, Nairobi: UN-HABITAT (accessed 23 November 2021)

UN-HABITAT (2020b) UN-Habitat COVID-19 Response Plan, Nairobi: UNHABITAT (accessed 23 November 2021)

Wiesel, I. and Liu, F. (2021) 'Conceptualising Modes of Redistribution in Public Urban Infrastructure', Urban Studies 58.8: 1561-1580, DOI: 10.1177/0042098020913188 (accessed 23 November 2021)

Zon, H.; Pavlova, M.; Drabo, K.M. and Groot, W. (2017) 'Municipal Health Services Provision by Local Governments: a Systematic Review of Experiences in Decentralized Sub-Saharan African Countries', Health Policy and Planning 32.9: 1327-1336, DOI: 10.1093/heapol/czx082 (accessed 23 November 2021) 


\section{Annexe 1.1: Questionnaire}

We expect this survey will take $15-20$ min of your time. We request a response by 24 th of March 2021. If you require more time, please get in touch!

By participating in this survey, you will inform the background study for UCLG's 2021 Policy Paper on Development Cooperation \& Local Governments. This is an important initiative to update UCLG's 2013 Policy Paper, found here: http://cib-uclg.org/ciblibrary/content/policy-paper-development-cooperation-and-local-governmentbackground-paper. This survey is also one of the ways to identify the case studies which will be developed in the background study.

The study is being led by Dr Jaideep Gupte, Institute of Development Studies UK, who can be reached for any questions in relation to this study at j.gupte@ids.ac.uk. A reference group set up for this study includes representatives from the Region of Catalonia, FCM and the CIB secretariat. The reference group can be reached through uclg.cib@vng.nl

In line with data regulations, all responses will be treated strictly confidentially and will be used only for scientific purposes and cannot be tracked back to you or your organization. Based on your responses we may request a follow-up interview with you. If you agree to participate in a follow-up interview or workshop, please provide your consent by responding in the appropriate section.

Thank you for your time!

The study will be carried out as follows: 


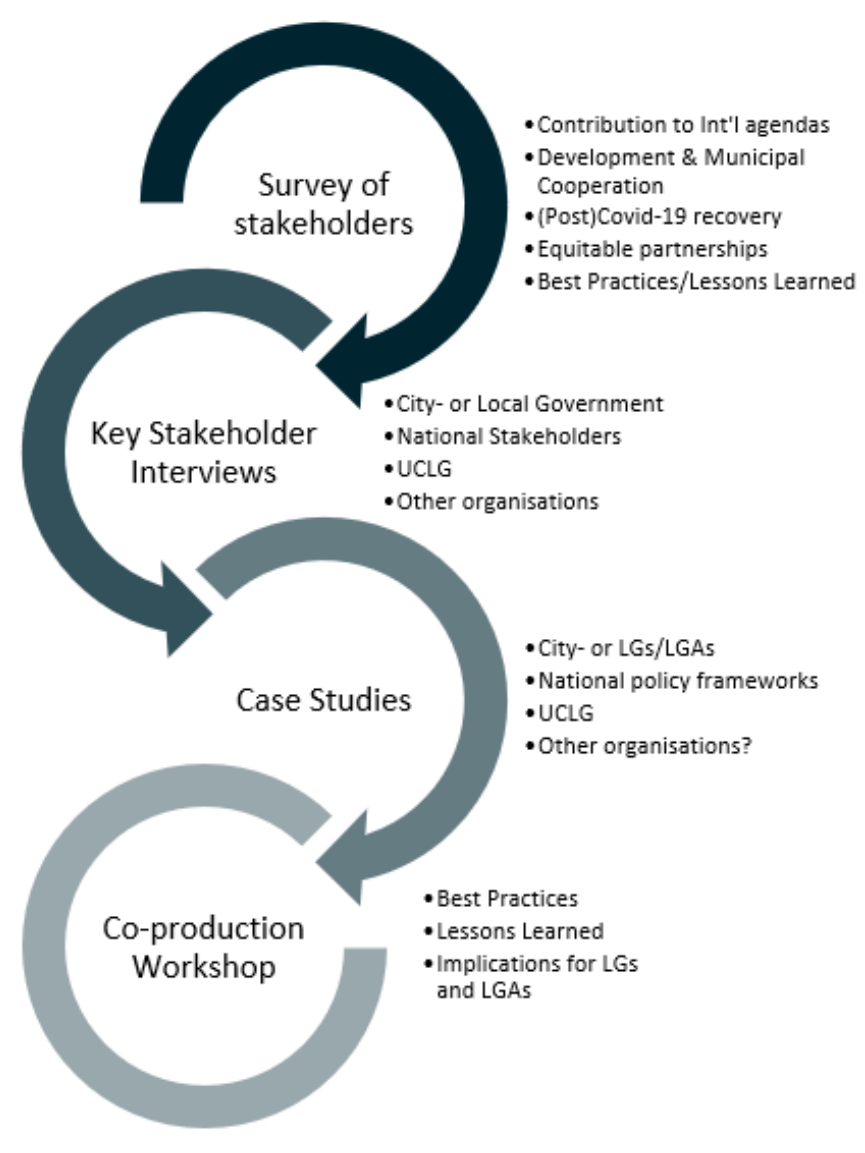

A) YOUR BASIC INFORMATION

Name

Surname:

Email:

Confirm email:

City:

Country/Region:

Organization:

Organization type

- Local government

- Regional government

- National government

- Local government association

- Regional government association

- Multilateral organization

- Non-governmental organization

- Academic or research institution

- Other:

Job title: $16^{\text {th }}$ March 2021:

Survey opens

$24^{\text {th }}$ March: Survey

closes

$24^{\text {th }}$ March $-8^{\text {th }}$ April:

Key stakeholder

interviews

$6^{\text {th }}-12^{\text {th }}$ April: Drafting

of first text and case

$20^{\text {th }}$ April: Workshop with

CIB members

$30^{\text {th }}$ April: Input for policy

statement ready

19-20 $0^{\text {th }}$ May: UCLG Exec

Bureau

October/November

2021: Final Paper;

UCLG World Council 


\section{--START OF SURVEY--}

\section{SECTION ONE: Understanding your organization's contributions to international agendas and tackling key challenges areas}

Q1.1 On which topics has your organisation been working on in the last 5 years

[Select all that apply, but in order of importance to your organisation]

1. No poverty

2. Zero hunger

3. Good health and well-being

4. Quality education

5. Gender equality

6. Clean water and sanitation

7. Affordable and clean energy

8. Decent work and economic growth

9. Industry, innovation and infrastructure

10. Reduced inequalities

11. Sustainable cities and communities

12. Responsible consumption and production

13. Climate action

14. Life below water

15. Life on land

16. Promoting peaceful and inclusive societies

17. Global partnerships

Q1.2 Describe briefly the current role of your organization in delivering or monitoring the Sustainable Development Goals (SDGs) by 2030:

Q1.3 During the last 5 years, what type of evidence has mostly influenced the actions of your organisation?

Research (analyses, studies, observations). [1]

Knowledge and information (consultations, internet, published documents). [2] Ideas and interests (expert opinions and views shaped by personal insights). [3] Politics (government agendas, political assessments and opportunities). [4] Economics (financial implications, economic evaluations and opportunity cost).

[5]

Q1.4 Is your organization providing data about its contributions to the UN 2030 Sustainable Development Agenda to other institutions such as foreign governments or international organizations? 


\section{IF YES}

Please describe briefly which data is being shared with other institutions.

The background study will contextualise UCLG's five priority themes ${ }^{29}$ in relation to the state of global grand challenges today. This begins most prominently with (post)COVID19 recovery, and the urgency of the final decade of the 2030 Agenda, moving to key milestones and commitments in the New Urban Agenda (cities, localisation), Paris Agreement (climate, net zero), Sendai framework (risk reduction and resilience), Addis agenda (local finance) and the Beijing declaration (gender).

Amongst contemporary issues driving global grand challenges today, the study will focus on:

- Ecological transformation and the multiple and cascading risks faced by leastresourced and most-marginalised urban and rural residents (particularly in, but not limited to, low- and middle-income countries). The study will chart the burgeoning transition from crisis management to multi-hazard risk-informed urban planning and decision-making.

- (Post)Covid-19 recovery: Covid-19, its impacts and the consequences of policy and individual responses require reflection of course. But the key for the localisation/decentralisation cooperation agenda is to ascertain longer term and broader health systems implications. The study will draw on CIB's position on COVID-19 and the responsibilities/competence of local governments in awareness raising, provision of key infrastructure and services, as well as collaboration.

- Addressing gendered and socio-economic inequalities in accessing basic services and infrastructures: the world is facing a $\$ 15$ trillion infrastructure gap by 2040.1 in 3 people globally do have access to safe drinking water and sanitation, while over half of the world's population do not have access to adequate and affordable health services. In cities and towns, close to 1 billion people live in under-serviced informal settlements. The study will revisit the continued role of local governments as key providers of public services and agents responsible for education, health and housing policies, and protectors of rights regardless of peoples' gender or legal status.

- Green finance: the study will situate sustainable strategies for financing local development that are an urgent and universal imperative.

Q1.5 Reflect on these key challenge areas and implications for cities and local governments. Which challenge area is most closely associated with your work? [Pick one]

Ecological transformation

(post) Covid19 recovery

\footnotetext{
29 1- Opportunities for all, culture and city diplomacy; 2- Right to the City and Inclusive Territories; 3- Territorial, multilevel governance and sustainable financing; 4- Safer, resilient and sustainable cities capable of facing crises; 5- Implementation of the New Urban Agenda
} 
Gendered inequalities and unequal access to basic services and infrastructure Green finance

Other global challenge: please describe the challenge in as much detail as possible. Please also indicate if we can follow up with you to understand this challenge area better

Allow follow up

Q1.6. Consider that traditional income or consumption-based measures may not provide adequate detail on how people experience these challenges. How does your organisation identify vulnerable/at-risk groups or organisations?

Q1.7 If there are reports or documents produced by your organisation or network in the past 5 years that can help us understand your organization or network's contributions to international agendas and tackling key challenges areas, please provide the details and links below:

\section{SECTION TWO: Municipal or international cooperation practices}

Q2.1 Has your organization been engaged in development cooperation initiatives involving local and/or regional governments?

Yes / No

\section{IF YES}

Q2.2 What modalities or mechanisms of development cooperation has your organisation used most during the last 5 years?

Examples include Financial transfers; Capacity support (technical assistance, training or knowledge exchange); Policy change (changes in rules and activities); Others. Please provide as much detail as possible

Q2.3 Describe the three main initiatives your organisation has been engaged with in terms of development cooperation during the last 5 years.

A) Name of initiative:

Objective: 
B) Name of initiative:

Objective:

C) Name of initiative:

Objective:

Q2.4 Name the three main partners of your organisation in terms of development cooperation during the last 5 years. This may be based on importance of challenge area; political significance; financial contributions etc

D) Name of partner:

E) Name of partner:

F) Name of partner:

Q2.5 What are your main reflections, positive or negative, in terms of your organisation's experience in development cooperation initiatives? Please explain your answer

Q2.6 Considering the experiences of your organization, what recommendations would you give to improve the policy context in which development cooperation practices are being currently implemented?

\section{SECTION THREE: (Post) Covid-19 recovery}

Q3.1 Has the work of your organisation changed since the COVID-19 crisis?

Yes / No

\section{IF YES}

Q3.2 How has the work of your organisation been affected?

Q3.3 What are your perspectives about the role of local and regional governments during the COVID-19 crisis and its aftermath?

Q3.4 Does your organisation currently belong to or collaborate with the United Cities and Local Governments (UCLG) network? 
Yes / No

\section{IF YES}

Q3.5 What role that you think UCLG, its members and its network could play in the aftermath of the COVID-19 crisis? Reflect specifically on development cooperation:

Q3.6 In general, what role do you think local governments, or local government associations, should take in addition to their current role in the aftermath of the Covid19 crisis?

Q3.7 How do you think the following development cooperation activities are being affected by COVID-19? (e.g., distant delivery, no international travel; write Don't know/Can't say if appropriate)

Monitoring \& evaluation:

[Open answer]

Learning:

[Open answer]

Implementation:

[Open answer]

\section{SECTION FOUR: Partnerships}

Q4.1 What type of cooperation partnerships best describe the ones your organisation is involved in? Select all that apply in order of importance to your organisation:

Within your city or local region.

National or regional.

With partners in the global South

With partners in the global North

Q4.1a Would you describe your organisation as based in global North

global South

both (for example is a network across North and South)

Q4.2 What has your organisation's role been in building equitable partnerships in international development cooperation? Be as detailed as appropriate

\section{SECTION FIVE: Lessons learned and best practices}


Based on your overall experience of development cooperation mechanisms and practices,

Q5.1. What has worked particularly well over the past 5 years? (e.g. level of financing; methods of partnerships; goals/target setting; role of scientific research and evidence; etc)

Q5.2. What lessons can be learned from mechanisms or practices that have not worked as well? (e.g. level of financing; methods of partnerships; goals/target setting; role of scientific research and evidence; etc)

Q5.3 Do you have any other remarks you want to make/share?

\section{SECTION SIX: Case studies}

Q6.1Based on your responses to this survey would you like to work with us to develop a case study of your city, local government or network?

$[\mathrm{Y} / \mathrm{N}]$

Q6.2 If Yes, please describe IN BRIEF your idea:

Q6.3 If Yes, please provide contact details of appropriate stakeholders who can provide relevant information and attend a workshop. We will then be in touch to arrange a more in-depth interview.

Name:

Role in Organisation:

Contact details:

Thanks again for your time! 


\section{Annexe 1.2: Workshop Breakout Activity}

Workshop on Local Government and Decentralised Cooperation [8 ${ }^{\text {th }}$ June 2021] Breakout Groups

\begin{tabular}{|c|c|}
\hline & \\
\hline $\begin{array}{l}\text { (existing and potential)? } \\
\text { Prompts: In your group, ask participants to bring up } \\
\text { examples around engagement within decentralised } \\
\text { cooperation which is centred around (i) multi-layered } \\
\text { cooperation which includes hyper local, regional, and } \\
\text { globally connected cooperation; (ii) multi-dimensional } \\
\text { cooperation which includes north-south, south-south, and } \\
\text { north-south-south relationships; (iii) driven to tackle } 21^{\text {st }} \\
\text { century grand challenges. } \\
\text { You should think of specific examples from their } \\
\text { organisations that have worked in the past, or suggestions } \\
\text { about what they are planning to do for increased } \\
\text { engagement with authorities, local actors, international } \\
\text { partnerships. }\end{array}$ & $\begin{array}{l}\text { What examples or lessons can you provide of } \\
\text { ‘learning to advocate for change together'? } \\
\text { Prompts: In your group, ask participants to bring up } \\
\text { examples around engagement within decentralised } \\
\text { cooperation which is centred around (i) multi-layered } \\
\text { cooperation which includes hyper local, regional and } \\
\text { globally connected cooperation; (ii) multi-dimensional } \\
\text { cooperation which includes north-south, south-south, } \\
\text { and north-south-south relationships; (iii) driven to } \\
\text { tackle } 21 \text { st century grand challenges. } \\
\text { You should think of specific examples from their } \\
\text { organisations that have worked in the past, or } \\
\text { suggestions about what they are planning to do for } \\
\text { increased engagement with authorities, local actors, } \\
\text { international partnerships. }\end{array}$ \\
\hline & \\
\hline $\begin{array}{l}\text { Ethics and Risks } \\
\text { Leading question: To what extent do current local and } \\
\text { decentralised cooperation efforts directly engage } \\
\text { citizens? - [Use a traffic light system of green/amber/red } \\
\text { to denote the extent of engagement and state why using } \\
\text { examples] } \\
\text { Follow-up questions: What lessons have we learned on } \\
\text { furthering citizens' rights and freedoms through cooperation? }\end{array}$ & $\begin{array}{l}\text { Financing } \\
\text { Leading question: How flexible is the current } \\
\text { financing available for cooperation? ('flexibility' in } \\
\text { the modes and mechanisms of funding, to } \\
\text { respond to changing risks and needs) - [Use a } \\
\text { traffic light system of green/amber/red to denote } \\
\text { the level of flexibility and state why using } \\
\text { examples] }\end{array}$ \\
\hline
\end{tabular}




\begin{tabular}{|c|c|}
\hline $\begin{array}{l}\text { How can we build trust and inclusion into concrete } \\
\text { partnerships? } \\
\text { Prompts: In your group, ask participants to bring up } \\
\text { examples around engagement within decentralised } \\
\text { cooperation which is centred around (i) multi-layered } \\
\text { cooperation which includes hyper local, regional and globally } \\
\text { connected cooperation; (ii) multi-dimensional cooperation } \\
\text { which includes north-south, south-south, and north-south- } \\
\text { south relationships; (iii) driven to tackle } 21 \text { st century grand } \\
\text { challenges. } \\
\text { You should think of specific examples from their } \\
\text { organisations that have worked in the past, or suggestions } \\
\text { about what they are planning to do for increased } \\
\text { engagement with authorities, local actors, international } \\
\text { partnerships. }\end{array}$ & $\begin{array}{l}\text { Follow-up question: What are the lessons learned } \\
\text { from successful fund-raising strategies? What are } \\
\text { some examples of innovative fund-raising } \\
\text { opportunities? } \\
\text { Prompts for the moderator: In your group, ask } \\
\text { participants to bring up examples around } \\
\text { engagement within decentralised cooperation which } \\
\text { is centred around (i) multi-layered cooperation which } \\
\text { includes hyper local, regional and globally connected } \\
\text { cooperation; (ii) multi-dimensional cooperation which } \\
\text { includes north-south, south-south, and north-south- } \\
\text { south relationships; (iii) driven to tackle } 21^{\text {st }} \text { century } \\
\text { grand challenges. } \\
\text { You should think of specific examples from their } \\
\text { organisations that have worked in the past, or } \\
\text { suggestions about what they are planning to do for } \\
\text { increased engagement with authorities, local actors, } \\
\text { international partnerships. }\end{array}$ \\
\hline
\end{tabular}




\section{Annex 2: Detailed Case Studies}

\section{\#1 Pivoting to online learning during the pandemic}

This case underscores the different layers of development cooperation that were responsive to challenges brought forward by the global pandemic.

Key contact: Hendra Adi (Training coordinator, UCLG-ASPAC) ${ }^{30}$

Region, focus country: Asia Pacific, Indonesia

Funded by: EU's LOCALISE SDGs programme

Scale: 6 coaching clinics from $07-2020$ to $12-2020$ organised once a month

Description:

With the help of online platforms, UCLG ASPAC has organised consultation clinics to create synergies between national and local governments. This was made possible through 'coaching clinics', where technical experts and coaches from non-state actors and national ministries advised local governments on amending local regulations and guidelines due to covid-19. LGs were provided a space to consult and ask questions to experts through these clinics. They also learned to use new technologies for online consultation, which UCLG ASPAC continues to advocate as efficient and effective, and to use where necessary.

In these clinics, the main topics of discussion included inter alia: i) alternative financing for environment, ii) food security, iii) economic digitalisation, iv) data integration (for social safety net), v) tourism and vi) online health service (telemedicine).

\section{Best Practices:}

$\rightarrow$ Moving quickly: Rapid shift to digital infrastructures by local and national authorities were enabled by flexible and responsive donor practices.

$\rightarrow$ Handholding: Success of the online courses in large part to an analogue 'matchmaking' initiative connecting local governments with a range of local level actors such as food vendors, tourism businesses, tele-medicine organisations, and NGOs. It is good practice to maintain an analogue or physical presence even if the course material is online.

$\rightarrow$ Assessing the right technologies: often the most expensive platforms are not suited for local needs.

\section{Challenges:}

$\rightarrow$ Needs and requirements change: Moving from in-person to online trainings was challenging, and UCLG ASPAC had to redesign the trainings to fit the online format.

\footnotetext{
${ }^{30}$ For further information please contact UCLG's Capacity and Institution Building Working Group uclg.cib@vng.nl
} 
$\rightarrow$ Disparity in access to digital infrastructure: Use of digital platforms was challenging in areas with severe connectivity issues. Women and men face different barriers to access digital services.

$\rightarrow$ Language barriers: The ASPAC team that undertook trainings relied on their local language to communicate with individuals signing up from countries such as Malaysia. Interpreters were required, as were additional resources for translators. Platforms such as Zoom have translation functions, but these often have cost implications.

\title{
Examples:
}

$\rightarrow$ Two LGs from Maluku Province and Gorontalo City have considered and successfully obtained loans from the third party (PT SMI) after attending a coaching clinic session. You can find more about PT SMI here.

$\rightarrow$ The LGs participating in the tourism recovery coaching session gained the awareness and capacity to encourage the local tourism recovery by developing the virtual tour programme and help to develop local tourist attractions as well as local products, to wider audiences through the programme.

$\rightarrow$ The tax payment reform was initiated by the increasing use of mobile devices that make the citizens aware of new technologies and how to use the smartphone for business purposes. The LGs caught the opportunity by creating a platform for online tax payment which supports the government's Covid-19 response.

$\rightarrow$ A LG from Bengkulu City successfully made a follow up to build partnership with BAZNAS (Indonesia's National Zakat Agency) in support of SDGs attainment in Bengkulu. For brief information about BAZNAS in English click here.

\section{References:}

"We see the importance of having consultation clinics as more like a guidance coming from national governments to the local governments to deal with the local situations. So it was responding to the clear and immediate need of the pandemic situation." (Interviewee from UCLG-ASPAC)

\section{Resources:}

All materials were prepared in Indonesian language. They can be accessed through following links:

\author{
Coaching Clinic \#3 \\ Coaching Clinic \#4 \\ Coaching Clinic \#5 \\ Coaching Clinic \#6
}




\section{\#2 Decentralised cooperation through Local Economic Development}

This case showcases how local governments are being capacitated under key development cooperation initiatives to undertake local economic development in their constituencies.

Key contact: Dzung Nguyen (Regional Programme Coordinator, PMI-LED), Lucy Slack (Deputy Secretary General, CLGF) ${ }^{31}$

Region, focus country: SE Asia, Vietnam; Southern Africa, Zambia

Levels of governance: Municipal, national, regional

Funded by: FCM \& CLGF

\section{Description:}

Development cooperation initiatives such as Partnerships for Municipal Innovation (PMI-LED) led by the Federation of Canadian Municipalities (FCM) and CLGF-led LED projects in African regions have focused on building capacities of local governance structures to address economic challenges. The FCM, for example, has focused on generating funds for local governments (such as in Vietnam among other countries) as well as building capacities of local governments and municipalities. CLGF's work has also focused on supporting local councils, and understanding local value chains, as well as building capacities of staff and local government leaders.

PMI's Local Innovation Fund (LIF) is a small fund made to local governments, their partners, and communities to address economic challenges in Cao Lanh, Vietnam. The structure of the LIF is principled on good governance, civic engagement, sound planning, transparency, and accountability. The LIF also strengthens project management capacities of the local governments that receive funds. CLGF's programmes have focused on creating an enabling environment to institutionalise LED grounded within national guidelines or frameworks.

\section{Best Practices:}

$\rightarrow$ Seed funding: Motivates local initiatives, makes them achievable through a competitive process and transparent appraisal, and ensures local continuation after the fund with resources mobilised from the private sector, community, and state budget.

$\rightarrow$ Use of intellectual property rights to implement projects successfully.

$\rightarrow$ Developing monitoring tools focused on environmental sustainability with consultations from LIF grant holders and beneficiaries.

$\rightarrow$ Understanding local value chain concepts with local governments and entrepreneurs to promote inclusive growth, productivity, and production, and to reduce supply costs.

\footnotetext{
${ }^{31}$ For further information please contact UCLG's Capacity and Institution Building Working Group uclg.cib@vng.nl
} 
$\rightarrow$ Identifying business opportunities at the city level by working closely with LED communities.

Challenges in setting up business opportunities at the local level:

$\rightarrow$ Low human resources and LED expertise in particularly in smaller regions and towns.

$\rightarrow$ Mobilising local resources for matching fund conditioned by the LIF application.

$\rightarrow$ Administrative bottlenecks at the city level: that require authorisation of the city leading to approval procedures from the national or regional government.

\section{Examples:}

$\rightarrow$ In Cao Lanh, the LIF has been directed in areas of;

i. employment and business generation for women and youth;

ii. capacity building - entrepreneurial training for informal workers, strengthening women's business support networks and organisations

iii. regional economic development and trade;

iv. business attraction, retention and investment (BARE) models and tools;

v. climate change mitigation and the green economy (by encouraging investment)

$\rightarrow$ The Ministry of Local Government and the Local Government Association of Zambia (LGAZ), as well as the Chalimbana Local Government Training Institute (CLTGI) have empowered through the development of LED guidelines and the implementation of both the Decentralisation Policy and the National Development Plan.

$\rightarrow$ As part of its LED strategy, the Chipata Municipal Council (Zambia) decided to promote investment and has established an interdepartmental team of council officials to engage investors.

Resources:

"Local Economic Development as a Driver of Trade in the Commonwealth" CLGF 


\section{\#3 City to city learning}

This case emphasises on the transfer of knowledge and good practices through citycity cooperation which has contributed to sustainable local development of cities.

Key contact: Jordi Cortes, Barcelona City Councili2

Region, focus country: South Africa, Mozambique and Barcelona

Levels of governance: National, Municipal, Sub-municipal

Funded by: City of Barcelona

\section{Description:}

Bi-lateral city-to-city projects between the city of Barcelona and the municipalities of Maputo have allowed for the exchange of city-city experiences in municipal management and local governance. Barcelona's efforts at strengthening North-South relationships has fostered exchange of knowledge, objectives and visions across North-South geographies. In particular, this form of collaboration goes beyond an institutional relationship between two municipal governments and involves specific involvement of many government departments.

\section{Best Practices:}

$\rightarrow$ Boost effectiveness of municipal policies by targeting vulnerable and excluded populations in Maputo's informal areas.

$\rightarrow$ Transferring knowledge on systematic and methodological innovation.

$\rightarrow$ Strengthening socio-cultural participation of citizens by promoting libraries and education through various initiatives.

$\rightarrow$ Strengthening technical and human skills of the Municipality of Maputo through the training of municipal technicians.

\section{Examples:}

$\rightarrow$ The Habitat Project has introduced a unique methodology called the 6 steps of DUAT to enable low-income, informal settlements acquire secure land titles and infrastructures such as wider street spaces. Several neighbourhoods in Chamanculo (Maputo), have obtained DUAT and seen a revival of the streetscape as a social space.

$\rightarrow$ Through the 6 steps to DUAT, access to (formal) land is sought through involvement processes and negotiation between public authorities (who own the land legally) and residents.

\footnotetext{
${ }^{32}$ For further information please contact UCLG's Capacity and Institution Building Working Group uclg.cib@vng.nl
} 


\section{\#4 Intercultural and heritage responses to development challenges through VLRs}

Since the First World Public Meeting on Culture in 2002 and the approval of Agenda 21 for Culture in 2004, LRGs and LRGAs have increasingly placed a cultural dimension within their public policies responding to developmental challenges. This case underscores how LRGAs that work on advocating cultural and heritage rights operationalise their intercultural and heritage rights policies.

Key contact: Jordi Pascual ${ }^{33}$

Region, focus country: Global

Levels of governance: Regional National (national associations)

Funded by: Various institutions and govts

\section{Description:}

The United Cities and Local Governments (UCLG), the International Council on Monuments and Sites (ICOMOS), the International Federation of Library Associations and Institutions (IFLA), the International Federation of Coalitions for Cultural Diversity (IFCCD), and the Culture Action Europe showcase their coming together in the Culture 2030 Goal Campaign report. UCLG's efforts in prioritising culture in sustainable development can be seen through the formation of a Culture Committee, as well as its longstanding work on publishing a range of documents with the overarching objective of linking culture with sustainable development at the local level.

International Council on Monuments and Sites (ICOMOS) has been working on the integration of culture and heritage into a range of development issues such as sustainable urban-rural development, tourism, climate action, and disaster preparedness.

International Federation of Library Associations and Institutions (IFLA) has continued its mission of advocating for libraries to support individuals and societies with the right to information. International Federation of Coalitions for Cultural Diversity (IFCCD). Culture Action Europe has largely focused on advancing local and European understanding of the connection between culture and local development in cities.

\section{Best Practices}

$\rightarrow$ Align values and objectives across partnerships.

$\rightarrow$ Binding governments all over the world to integrate culture in their sustainable development goals through policy drafting processes.

$\rightarrow$ Managing data through databases on good practices covering a range of cities.

\footnotetext{
${ }^{33}$ For further information please contact UCLG's Capacity and Institution Building Working Group uclg.cib@vng.nl
} 


\section{Examples:}

$\rightarrow$ Using Voluntary Local Reviews (VLRs) and National Local Reviews (NLRs) to highlight usage of terms relating to culture and heritage in national and city government's development goals. 


\section{\#5 Decentralised cooperation for peacebuilding in fragile contexts}

This case highlights how peacebuilding efforts by municipalities in conflict affected settings have led to social cohesion among local communities.

Key contact: Sanne van Amerongen, VNG International ${ }^{34}$

Region, focus country: Middle East, Lebanon

Levels of governance: National, Municipal, Sub-municipal:

Funded by: Municipality of Arsal

\section{Description:}

As a result of the 2014 Syrian invasion by the IS, many refugees from neighbouring Syria settled in Arsal occupying spaces informally. The Lebanese host communities over time developed a sense of fear from Syrian refugees who were perceived as supporters of the insurgents. To secure peace in the city, the municipality of Arsal has been at the forefront of creating opportunities for social cohesion between different communities residing in Arsal. It has organised interventions to facilitate different groups who may be equally vulnerable to conflict. There is intense competition for resources (livelihood opportunities), and essential public infrastructures among these groups.

\section{Best Practices:}

$\rightarrow$ The municipality as an enabler for dialogue between communities that are hostile to each other.

$\rightarrow$ Compensation for infrastructural damages. The municipality of Arsal, despite a lack of funds, finds that compensation for restoration reduces escalation of conflict.

$\rightarrow$ Reconciliation and redressal: Linkages with national government and security services to protect communities from violence such as harsh treatment and sentencing.

\section{Example}

$\rightarrow$ Dialogue of Life's strategy aims to solve potential conflicts before these escalate. When a conflict arises between two parties, the municipality organises "Sulha" (mediation) sessions to bring their points of view closer and prevent them from fighting each other.

\section{Resources:}

IFLA report

\footnotetext{
${ }^{34}$ For further information please contact UCLG's Capacity and Institution Building Working Group uclg.cib@vng.nl
} 


\section{\#6 Creating space for women in urban science and practice}

Ensuring women's participation in local decision-making processes and enabling equal representation in social, political, and economic domains have been key areas of work for LRGs, LRGAs and their constituencies. This case focuses on how mentoring is being adopted as a pathway for equal participation of women in urban science and urban practice.

Key contacts: UCLGA Director - Jacqueline Moustache-Belle - Director Gender and Youth UCLGA, Lucy Slack, Director General, CLGF ${ }^{35}$

Region, focus country: UCLG Africa, Africa and Europe

Levels of governance: Municipal, national, regional

Funded by: Governments and international bodies

\section{Description:}

Through the REFELA network, UCLGA brings together African women mayors and locally elected representatives for gender sensitive local governance. This approach is grounded in strong advocacy within national governments and political parties. Using SDG 5.5.1b goal as its guiding pillar, the Commonwealth Women in Local Government Network through CLGF has adopted a transformative feminist mentorship approach to build leadership capacities of women who are already elected and raise participation of women who are aspiring to hold public office.

Other examples include:

Sweden's national government calls itself "the feminist government". Through its longstanding work on creating mechanisms for equal power for both men and women, Swedish government has supported the creation of gender working groups in focal points in municipalities and LGAs and activities that help adopt a gender equality perspective.

Canada's Feminist International Assistance policy approach focuses on supporting investments, partnerships, innovation and advocacy efforts that have the greatest potential to close the gender gap and increase participation of vulnerable and marginalised groups in key decision-making processes.

\section{Best Practices:}

$\rightarrow$ One-on-one mentoring sessions and consultations with mentors and mentees (newly elected candidates, or those aspiring to contest for local elections).

$\rightarrow$ Experiential learning: Mentors give mentees the opportunity to attend political meetings, run sessions, observe legislative meetings which provide them with the experience of navigating political spaces.

\footnotetext{
${ }^{35}$ For further information please contact UCLG's Capacity and Institution Building Working Group uclg.cib@vng.nl
} 
$\rightarrow$ Conducting trainings (designed) by local governments, associations, and political parties. These are on particular skills such as fundraising, record keeping, and financial management, as well as broader topics such as how to deal with sexual harassment.

$\rightarrow$ Forming of women's networks and alliances through collaborative learning. Women's groups of mentees and mentors from different regions have found that coming together by sharing stories have led to collaborative ways of learning and forming of networks across geographies.

\section{Challenges:}

$\rightarrow$ Capacity building and specialised technical tools, in order to strengthen the cities and Local Authorities that have joined the REFELA campaigns.

$\rightarrow$ Infrastructure and capacity required to maintain REFELA secretariats at least at regional level.

$\rightarrow$ Need to focus more on matching mentors with mentees according to values, personality, and expertise.

$\rightarrow$ Advocacy for cities and Local Authorities to obtain competent human resources and certified gender expertise, to enable the progress of gender equality especially in political campaigns.

$\rightarrow$ Barriers exist in terms of socio-cultural norms from a gender perspective.

$\rightarrow$ Limited access to technology and networks in grassroots spaces.

$\rightarrow$ Need to integrate monitoring with evaluation AND learning in programming.

\section{Examples:}

$\rightarrow$ To strengthen the capacities of key positions at the city level, REFELA-UCLG Africa focuses on training and visibility within its network. Academic training on local governance enables women and strengthens women's leadership to manage city affairs effectively. Recent trainings have focused on Gender sensitive budgeting, 'Guaranteeing women's rights at the local level', and Digital literacy to provide knowledge and enable administration through modern technology.

$\rightarrow$ Mentoring of younger, upcoming politicians by former REFELA presidents. Notably, these women leaders are often promoted to high positions of responsibility in their respective countries, such as Mauritania, Cameroon, Gabon.

$\rightarrow$ In country contexts where politics and leadership tend to be dominated by men, Swedish government's Advanced International Political Leadership Programme trains women in politics with tools and skills to improve their political leadership. This includes training in strategic planning and leadership, organising of study trips, thereby opening opportunities for elected women in municipalities. 


\section{References:}

“...having data on elected women at the local level (SDG 5.51b) will be really helpful for us at the global level because if you look at how we use the data of how many women parliamentarians there are, it's incredibly useful data in terms of how far we have got to go. Mentoring women as a mechanism for supporting leadership has been really interesting in terms of how people talk about mentoring. A lot of people talk about mentoring but actually very few are mentoring. There is a lot of training, and capacity building that's called mentoring - this is something we will do more on." (interviewee for UCLG-CIB policy paper)

\section{Resources:}

"A Review of Mentoring Programmes for Women's Political Advancement and Leadership" - CLGF 


\section{\#7 Advocacy for learning; learning as advocacy}

Learning initiatives can play an important role in fostering relationships between learning and advocacy. This example makes the case for digital space as an essential one for the relationship between learning and advocacy.

Key contact: Sara Hoeflich (UCLG Learning) ${ }^{36}$

Region, focus country: Europe, UCLG Learning members

Levels of governance: Municipal, national, regional

Resources: SDG Module 4 links, VLR

\section{Description:}

The engagement of communities and partners to work in decentralised cooperation is crucial, even more so if the SDG 17's call towards global partnerships for sustainable development is taken into consideration.

The digital space allows for fast connection, feedback and learning among leaders. After the COVID outbreak, UCLG demonstrated this in its Live Learning Experience cycle. Additionally, the digital space allows officers and staff in cities to connect and engage in the preparation of processes, and it is also a contest on the relevance of international policy development. The global connectivity is an opportunity to open relations and cooperation. Cities performance can be (voluntarily) measured. The VLR guidance work is a crucial starting point and so are the different benchmarking initiatives that appear in the network.

In person meetings are, however, important for long term relationships inside associations such as UCLG. They allow for a more spontaneous and emotional engagement. Leaders may find peers that share visions, technicians can understand trends, get in touch with networks, and distinguish between partners, opportunities and knowledge markets. Finally, the territorial experience - to build empathy with a place, its people and problems is inspiring for solidarity as well as for the application of practices and lessons learnt.

\section{Best practices:}

$\rightarrow$ Learning by doing: the construction of the Module 4 is inspired by practical findings of the network, in particular of a South-South and City to City cooperation.

$\rightarrow$ Investment in technical capacity for the development of Module 4. This module has been constructed by engaging particular cities and bringing Southern perspectives.

$\rightarrow$ Local government's expectation to find donors through international work and engagement in UCLG is very high and sometimes not realistic

\footnotetext{
${ }^{36}$ For further information please contact UCLG's Capacity and Institution Building Working Group uclg.cib@vng.nl
} 
$\rightarrow$ Fostering relationships across North-South: South-South and local geographies.

$\rightarrow$ Learning Modules to localise the SDGs. Online courses on localising the SDGs provide training for 80 people a year. There is a strong interest and support to the training approach, in particular regarding global agendas. Consequently, the UCLG Learning Forum gathers a growing community of practitioners and fosters complementing the work of the CIB Working Group and reaching out to LGA.

\section{Challenges:}

$\rightarrow$ Local government's expectation to find donors through international work and engagement in UCLG is very high and sometimes not realistic. Further, the training community that joins UCLG, in particular LGAs, is often biased and concentrated on pledges and messages, while the work of project design, monitoring and evaluation is considered too technical.

$\rightarrow$ The projects were a benchmark in peer-to-peer learning, and the relationships in African and Latin American countries still enjoy the trust created that time so the network is just refueled.

\section{Upcoming opportunities to strengthen the relationships between different} actors in development cooperation:

$\rightarrow$ Increased global connectivity through online resources provides an opportunity for more open relations and increased cooperation. City performance can be (voluntarily) measured, for which the VLR guidance work is a crucial starting point, in addition to the different benchmarking initiatives that are appearing in the network (UCLG Eurasia, Toronto).

$\rightarrow$ The opportunity of network learning around cooperation is visible in numerous practice platforms that have appeared (Guangzhou award, OIDP, PLATFORMA). The next step towards learning of cities and territories globally is increased, more transparent partnering and reporting. Possible practice schemes need to be simple, open, and aligned between each other, which will allow for more actors to join as well as for future generations to see the value of cities and territories working together.

\section{References:}

"Advocacy is not an isolated task, nor a strictly bilateral relation or motivation between receiver and donor. The advocacy for more and better cooperation requires knowledge of the political context, as well as examples and practice provided by other local actors (and international peers) that are able to learn from each other."

\section{Resources:}

UCLG Learning Module 4: Decentralised Cooperation

Voluntary Local Reviews 


\section{\#8 Capacity building of associations}

This case documents efforts undertaken by the Association of Flemish Cities and Towns (VVSG) to equip and build capacity of its sister association, the Association Nationale des Communes du Bénin (ANCB) in Benin to integrate gender equality at the local level.

Region, focus country: West Africa and Belgium

Levels of governance: Municipal (local authorities), National (national associations) Funded by: The Federal government of Belgium funded a five-year project

\section{Description:}

This work has primarily focused on enabling the municipalities of Benin on gender equality through partnership building, transfer of knowledge across associations, and provision of advisory support. Central to this project is the idea that 12 municipalities in Benin will first experiment how gender equality is implemented, and gradually this pilot will be scaled up to all 77 municipalities in Benin. These municipalities include Agbangnizoun, Bohicon, Dogbo, Houeyogbé, Lalo, Ouinhi, Toviklin, Za-kpota, Materi, Pèrèrè, Péhunco and Toucountouna. These pilot municipalities are supported by ANCB individually, but all of them come together every year to learn from each other through exchanging their experiences.

\section{Best practices:}

$\rightarrow$ Strengthening of local governance structures within the municipalities of Benin which provide a platform to discuss urgent concerns regarding gender citizen participation.

$\rightarrow$ Building partnerships with universities to develop strategies for gender equality at the local level.

$\rightarrow$ Organising cross-learning visits and across geographies.

Challenges:

$\rightarrow$ Social and cultural barriers existing not just in Benin but Belgium as well.

$\rightarrow$ Lack of expertise in gender equality.

\section{Examples:}

$\rightarrow$ VVG and ANCB have worked with University of Leuven (Belgium) and University of Parakou (Benin) to develop tools and templates that identify specific gender equality projects and activities in local policies.

$\rightarrow$ Female councilors who are part of Network of Locally Elected Women come together from their municipalities to identify topics that could be elevated for discussion at the national level.

$\rightarrow$ Organising study visits for Benin to learn from Belgian and Flemish Associations of how these municipalities work on gender. VVSG has also organised trainings for Flemish Associations to integrate gender equality. Over 
the course of the project, a conference was also organised to discuss gender equality agenda. 
Institute of Development Studies

Library Road

Brighton, BN1 9RE

United Kingdom

+44(0)1273606261

ids.ac.uk

Charity Registration Number 306371

Charitable Company Number 877338

(c) Institute of Development Studies 2022 